Florida International University FIU Digital Commons

\title{
Nano-Confined Metal Oxide in Carbon Nanotube Composite Electrodes for Lithium Ion Batteries
}

\author{
Alexandra J. Henriques \\ Florida International University, ahenr014@fiu.edu
}

DOI: $10.25148 /$ etd.FIDC001811

Follow this and additional works at: https://digitalcommons.fiu.edu/etd

Part of the Other Materials Science and Engineering Commons

\section{Recommended Citation}

Henriques, Alexandra J., "Nano-Confined Metal Oxide in Carbon Nanotube Composite Electrodes for Lithium Ion Batteries" (2017). FIU Electronic Theses and Dissertations. 3169.

https://digitalcommons.fiu.edu/etd/3169 


\section{FLORIDA INTERNATIONAL UNIVERSITY}

Miami, Florida

NANO-CONFINED METAL OXIDE IN CARBON NANOTUBE COMPOSITE

ELECTRODES FOR LITHIUM ION BATTERIES

A thesis submitted in partial fulfillment of the requirements for the degree of

MASTER OF SCIENCE

in

MATERIALS SCIENCE AND ENGINEERING

by

Alexandra J. Henriques

2017 
To: Interim Dean Ranu Jung

College of Engineering and Computing

This thesis, written by Alexandra J. Henriques, and entitled Nano-Confined Metal Oxide In Carbon Nanotube Composite Electrodes For Lithium Ion Batteries, having been approved in respect to style and intellectual content, is referred to you for judgment.

We have read this thesis and recommend that it be approved.

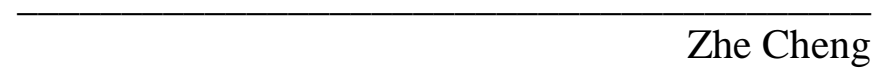

$\overline{\text { Norman Munroe }}$

Chunlei Wang, Major Professor

Date of Defense: March 31, 2017

The thesis of Alexandra J. Henriques is approved.

Interim Dean Ranu Jung College of Engineering and Computing

Andrés G. Gil

Vice President for Research and Economic Development and Dean of the University Graduate School

Florida International University, 2017 


\section{ACKNOWLEDGMENTS}

This work was partially supported by the National Science Foundation (NSF) projects (no. 1506640 and no. 1509735) and NERC ASSIST center seed funding. The author gratefully acknowledges the University Graduate School at FIU for the GPSC Travel award. The author is thankful for the help and support of the AMERI staff at FIU. The author owes gratitude to Dr. Yusuf Emirov at USF, Dr. Alexander Franco, and Dr. Shravana Katakam. The author thanks Dr. Wenzhi Li for collaborative efforts on this project. The author would like to thank Dr. Frank Urban for great classes and edifying discussions. The author thanks her committee members: Dr. Zhe Cheng, Dr. Norman Munroe, and Dr. Chunlei Wang as well as the current and former members of Dr. Wang's research group at FIU.

The author would like to thank, in particular, her parents, family, and friends for their patience, love, and support throughout the duration of the thesis work and preparation of this manuscript. Mary "Nan" H., thank you for all your prayers. Hamilton \& Lillian, Dan \& Latika, Sammie, Jackie, and Amanda \& Dan, I love you all and thank you for welcoming me into your extended families. Mary D., thank you for making me smile. Uncle Javi, thank you for the daily morning dose of sunshine and laughter. To my teammates, instructors, and friends at Better Families Through Tae Kwon Do: thank you for all of the support and for helping me keep my life in balance. To Luiza, Archana, Elnaz, and Michelle: thank you for being wonderful friends through it all. Richa, thank you for teaching me, for your mentorship

and guidance, and for your friendship during the toughest times. McKenzie, thank you for being the best support for thirteen years and counting. Mom, Dad, and Lizzie, thank you for your unconditional love and support. 


\title{
ABSTRACT OF THE THESIS \\ NANO-CONFINED METAL OXIDE IN CARBON NANOTUBE COMPOSITE ELECTRODES FOR LITHIUM ION BATTERIES
}

\author{
by \\ Alexandra J. Henriques \\ Florida International University, 2017 \\ Miami, Florida \\ Professor Chunlei Wang, Major Professor
}

Lithium ion batteries (LIB) are one of the most commercially significant secondary batteries, but in order to continue improving the devices that rely on this form of energy storage, it is necessary to optimize their components. One common problem with anode materials that hinders their performance is volumetric expansion during cycling. One of the methods studied to resolve this issue is the confinement of metal oxides with the interest of improving the longevity of their performance with cycling. Confinement of metal oxide nanoparticles within carbon nanotubes has shown to improve the performance of these anode materials versus unconfined metal oxides. Here, electrostatic spray deposition (ESD) is used to create thin films of nano-confined tin oxide/CNT composite as the active anode material for subsequent property testing of assembled LIBs. This thesis gives the details of the techniques used to produce the desired anode materials and their electrochemical characterization as LIB anodes. 


\section{TABLE OF CONTENTS}

CHAPTER

PAGE

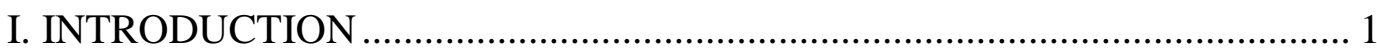

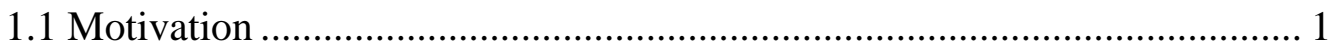

1.1.1 Metal Oxides as Anode Materials ................................................ 2

1.1.2 Nanostructure and Carbon Matrix ................................................. 3

1.2 Research objectives ....................................................................... 4

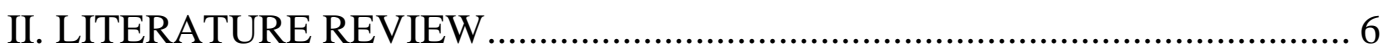

2.1 Rechargeable Batteries and Lithium Ion Batteries ........................................ 6

2.2 Metal Oxides as Anode Materials ............................................................ 7

2.3 Nanostructural Confinement of Metal Oxides in Carbon ............................. 9

2.3.1 Sn@Carbon Nanoparticles in Bamboo-like Hollow Carbon

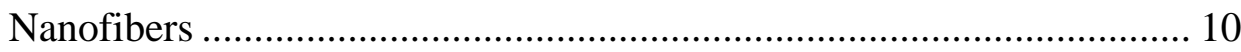

2.3.2 Comparison of $\mathrm{SnO}_{2}$ Based Anodes with Various Nanostructured

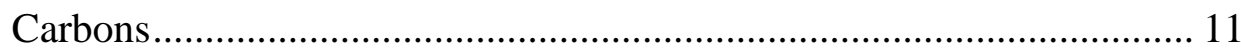

2.3.3 Nanoconfined $\mathrm{MnO}_{2}$ in CNTs.................................................. 12

III. EXPERIMENTAL TECHNIQUES AND METHODS ……………................ 15

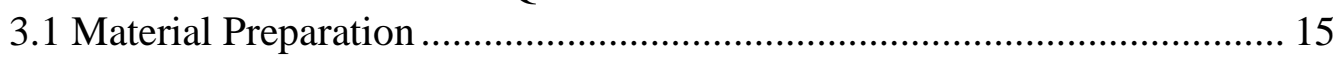

3.2 Electrostatic Spray Deposition (ESD) .................................................... 16

3.3 Structural and Morphological Characterization ....................................... 18

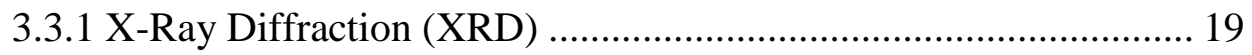

3.3.2 Scanning Electron Microscopy (SEM).......................................... 19

3.3.3 Transmission Electron Microscopy (TEM) ................................... 19

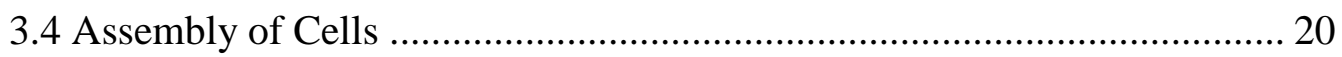

3.5 Electrochemical Performance Testing....................................................... 20

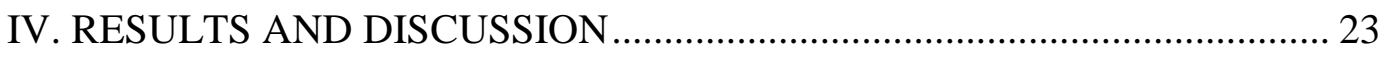

4.1 Characterization Results ...................................................................... 23

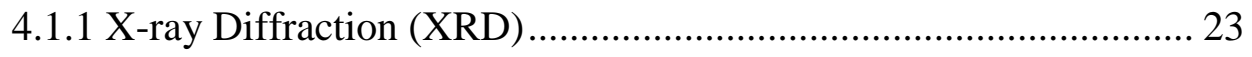

4.1.2 Scanning Electron Microscopy (SEM) ......................................... 24

4.1.3 Transmission Electron Microscopy (TEM) …………………….... 25

4.2 Electrochemical Results .................................................................... 28

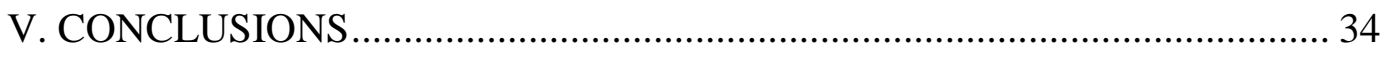

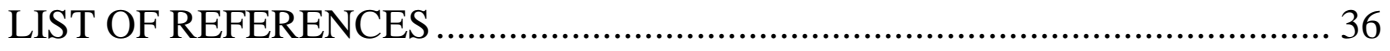




\section{LIST OF FIGURES}

FIGURE

PAGE

1. Specific capacities and potential vs. $\mathrm{Li} / \mathrm{Li}^{+}$for various anode materials ${ }^{3} \ldots \ldots \ldots \ldots \ldots \ldots . . . . . . . .2$

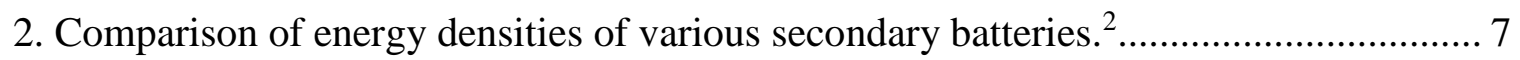

3. (a) Bright field (BF) zero-loss filtered elastic TEM image of CNFs with Sn@carbon nanoparticles and (b) Elemental mapping confirming the tin and carbon content in the predicted locations. ${ }^{15}$

4. (a) CV for Sn@carbon encapsulated in CNFs with scan speed of $0.2 \mathrm{mV} / \mathrm{s}$ (b-d)

Electrochemical performance vs. $\mathrm{Li}^{+} / \mathrm{Li}$ with cycling between 0.01 and $3 \mathrm{~V} .{ }^{15}$

5. (a) BF TEM micrograph of $\mathrm{MnO}_{2}$ confined within CNT, (b) $\mathrm{MnO}_{2}$ outside CNT, (cf) High angle area diffraction images and elemental analysis showing confinement of $\mathrm{MnO}_{2}$ within CNTs. ${ }^{14}$

6. (a) Specific capacitance comparison, (b) comparison of normalized specific capacitance between $\mathrm{MnO}_{2}$ outside vs. inside CNTs for composite anodes, (c) CV comparing CNTs without $\mathrm{MnO}_{2}$ to CNTs with $\mathrm{MnO}_{2}$ both outside and inside, (d) Tabulated values of specific capacitance and $\mathrm{MnO}_{2}$ normalized specific capacitance. ${ }^{14} .14$

7. (a) Schematic representation of the ESD process and (b) photograph of setup........... 18

8. XRD data for confined, unconfined, $\mathrm{SnO}_{2}$ alone, and CNT alone samples.

9. SEM of $\mathrm{SnO}_{2}$-in-CNT sample with (a) $97 \mathrm{x}$, (b) 550x, (c) 2,300x and (d) $75,000 \mathrm{x}$ magnifications

10. (a) and (b) TEM images showing an individual carbon nanotube, vertically oriented, with a tin oxide nanoparticle showing clear confinement with identification of the d-spacing between atomic planes (c) Profile of interplanar spacing for $d=2.6 \AA$ corresponding to $\mathrm{SnO}_{2}$. (d), and (e), showing confinement of $\mathrm{SnO}_{2}$ particles within CNTs.

11. Cyclic voltammetry curves for experimental and control group samples 29

12. Galvanostatic charge-discharge curves for $20 \% \mathrm{SnO}_{2}$-in-CNT sample 30

13. Cycle performances for the various control and experimental group samples 31

14. Cycle performance of $20 \% \mathrm{SnO}_{2}$-in-CNT for 200 cycles at $100 \mathrm{mAhg}^{-1}$ .33 


\section{ABBREVIATIONS AND ACRONYMS}

$\begin{array}{ll}\text { CNT } & \text { Carbon nanotube } \\ \text { CV } & \text { Cyclic voltammetry } \\ \text { EDS } & \text { Chemical vapor deposition } \\ \text { EIS } & \text { Electrochemical impedance spectroscopy } \\ \text { ESD } & \text { Electrostatic spray deposition } \\ \text { FESEM } & \text { Field-emission scanning electron microscope } \\ \text { HRTEM } & \text { High-resolution transmission electron microscopy } \\ \text { LIB } & \text { Lithium ion battery } \\ \text { MWCNT } & \text { Multi-walled carbon nanotube } \\ \text { RGO } & \text { Reduced graphene oxide } \\ \text { SEM } & \text { Scanning electron microscopy } \\ \text { TEM } & \text { Transmission electron microscopy } \\ \text { XRD } & \text { X-ray diffraction }\end{array}$




\section{CHAPTER I}

\section{INTRODUCTION}

The key objective of this master's thesis project was to create and test thin films of a lithium ion battery (LIB) anode active composite material made of tin oxide $\left(\mathrm{SnO}_{2}\right)$ and carbon nanotubes (CNTs). The chosen thin film deposition method was electrostatic spray deposition (ESD). This composite active material was specifically chosen to create a nanostructure with tin oxide nanoparticles confined within the inner channels of the carbon nanotubes with the goal of improving electrochemical performance. The composite material was characterized using x-ray diffraction (XRD), scanning electron microscopy (SEM), and transmission electron microscopy (TEM). Electrochemical studies were carried out via cyclic voltammetry $(\mathrm{CV})$, galvanostatic discharge-charge testing, rate capability testing, and electrochemical impedance spectroscopy (EIS). Electrochemical testing was used to determine the specific capacity of the active anode material of interest as well as the extent of retention of capacity with cell cycling. The research results show that the nano-confined $\mathrm{SnO}_{2}$-in-CNT composite materials are promising anodes for use in LIBs. Furthermore, the weight ratio of $\mathrm{SnO}_{2}$ to CNT that showed the best performance was 20:80.

\subsection{Motivation}

The development of high capacity rechargeable lithium-ion batteries (LIBs) is crucial given the insatiable energy demands that come with the rapidly developing technological landscape that exists in modern society. From portable technologies and medical equipment to alternative energy sources, the continual improvement of batteries 
and fuel cells has been rendered invaluable for society to continue improving. With the demand for renewable energy and electric vehicles, improved energy storage technology is necessary to enable an effective transition to more environmentally sound practices and energy infrastructure. ${ }^{1,2}$

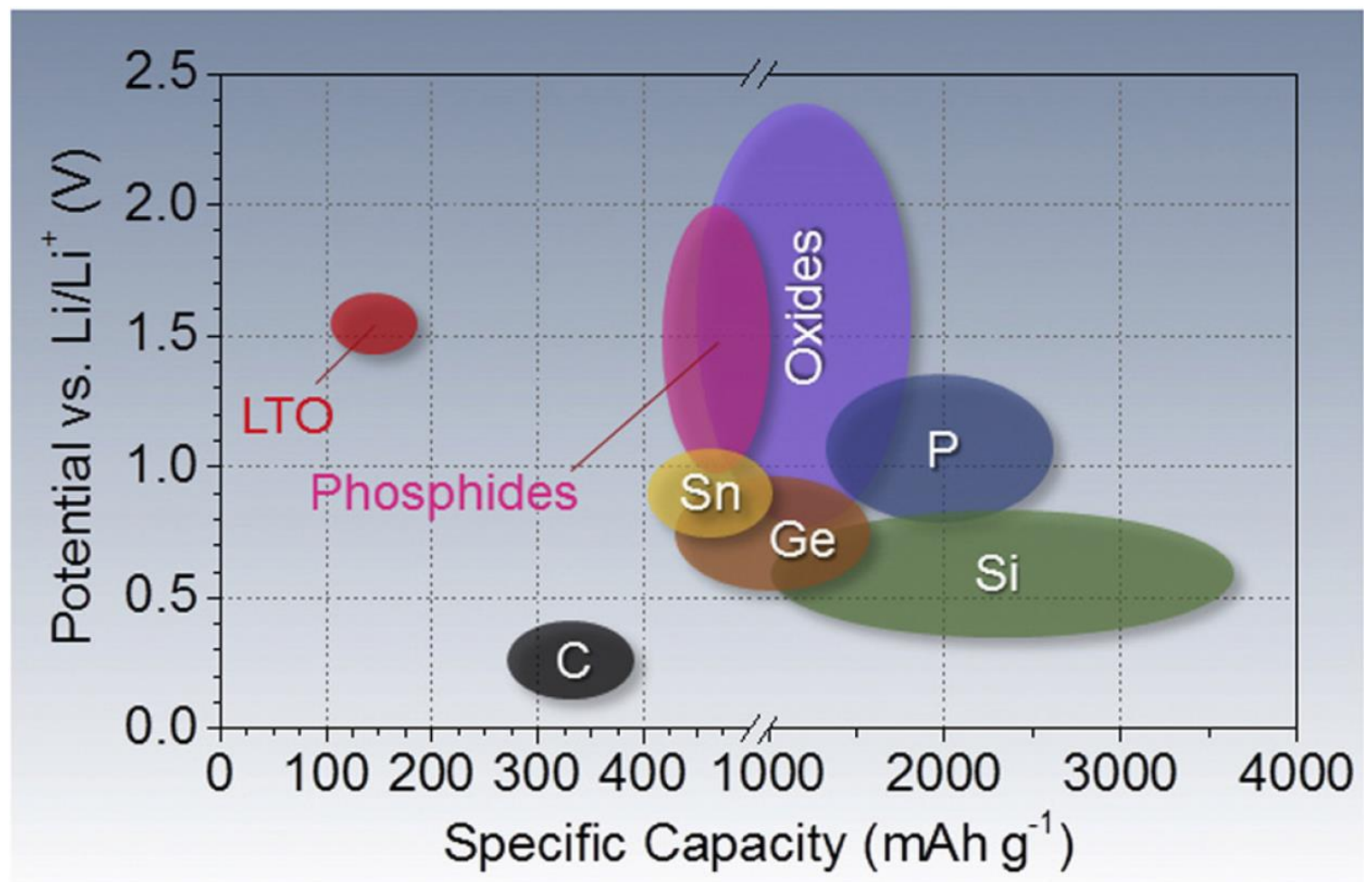

Figure 1: Specific capacities and potential vs. $\mathrm{Li} / \mathrm{Li}^{+}$for various anode materials ${ }^{3}$

\subsubsection{Metal Oxides as Anode Materials}

One of the major areas of research focus is the development of high performance advanced electrochemical materials for the electrodes of LIBs. Deviating from typical intercalation anodes such as graphite, metal oxides $\left(\mathrm{M}_{\mathrm{x}} \mathrm{O}_{\mathrm{y}}\right)$ with conversion and/or alloying reaction mechanisms have become one of the areas of research focus in recent years because of their high theoretical capacities as active anode materials. ${ }^{1}$ Figure 1 shows the 
specific capacities and potentials vs. lithium of various anode materials that have been explored. Carbon, which is presently a widely commercially used anode material, has a relatively low specific capacity, where as metallic tin and metal oxides, including tin oxide $\left(\mathrm{SnO}_{2}\right)$, have higher specific capacities. In this research, $\mathrm{SnO}_{2}$ was chosen as the metal oxide of interest because its theoretical capacity is more than twice that of the current anode of choice, graphite, with a theoretical capacity of $\sim 790 \mathrm{mAh} / \mathrm{g}$ for $\mathrm{SnO}_{2}$ versus $\sim 372 \mathrm{mAh} / \mathrm{g}$ for graphite. ${ }^{2,45}$ Additionally, anodes made with $\mathrm{SnO}_{2}$ active materials can be paired with a large variety of cathode materials because these anodes can work at a relatively low potential, similar to graphite and the material is inexpensive and nontoxic. ${ }^{4,5}$ The main drawbacks of the use of most metal oxides as an anode material in LIBs is their low electrical conductivity and their large volume change during cell cycling, which is true of $\mathrm{SnO}_{2}$ as well. ${ }^{1,2,4}$ Volumetric expansion of the anode material is associated with cracking, particle shuffling, and pulverization of the active material as well as its delamination from the current collector. ${ }^{1}$ Thus, a variety of solutions to these issues are being explored to better leverage the possible benefits of metal oxide anode materials.

\subsubsection{Nanostructure and Carbon Matrix}

One of the methods considered to solve the issue of the volumetric expansion during the cycling of cells with metal oxide-based anodes is the nanostructuring of the active material. ${ }^{1,2,4,6,7}$ Nanostructured anode materials offer the advantage of a greater surface area to volume ratio versus bulk or larger particulate materials. ${ }^{2}$ This allows for room to accommodate volume change, reducing the issues that typically cause capacity fading and eventual failure. ${ }^{2}$ A carbon matrix, such as a carbon nanotube-based matrix, is 
of interest given its improved electrical conductivity versus metal oxides and its good mechanical strength. ${ }^{8}$

\subsection{Research objectives}

The overall goal of this project was to synthesize a LIB anode material that confined tin oxide within a CNT structure and test it electrochemically. The secondary goals included:

(1) Testing of various weight ratios of $\mathrm{SnO}_{2}$ to CNTs in the composite active material to determine best electrochemical performance,

(2) Optimization of ESD parameters to create a porous thin film of the active material,

(3) Comparison of the electrochemical performance of the target material with control groups to validate the results, and

(4) Evaluation of material structure characteristics via SEM, TEM, and XRD to determine structure effects on electrochemistry.

The research hypothesis was that the creation of a thin film of tin oxide nanoparticles confined within CNTs via ESD will improve the performance of the tin oxide active material as a LIB anode by increasing interfacial charge storage, limiting its volumetric expansion, improving electrical conductivity, reducing byproduct aggregation, and buffering stresses generated during battery cycling.

The second chapter will present the relevant background information about LIB anode materials and the chemistry involved during the cycling of LIBs with carbon and tin oxide anodes as well as information about the chosen microstructure/nanostructure of the active anode material. Chapter three details the experimental methods used to create the 
active anode material of interest, assemble cells containing this material, electrochemical testing carried out on these cells, and additional characterization of the materials. Chapter four gives the results of the electrochemical testing and material characterization that was done and chapter five elucidates the conclusions drawn from the results obtained. 


\section{CHAPTER II}

\section{LITERATURE REVIEW}

This chapter contains a review of the relevant literature pertaining to rechargeable battery technology, lithium ion batteries, anode materials common in LIBs, and studies conducted on materials used for electrochemical storage with similarities in nanostructure or composition to the work presented in the subsequent chapters.

\subsection{Rechargeable Batteries and Lithium Ion Batteries}

Batteries are typically categorized as either primary or secondary based on their ability to be recharged. ${ }^{2}$ Primary batteries are those that are only used once and cannot be recharged. ${ }^{2}$ Secondary batteries, also called rechargeable batteries, are those that operate via a reversible chemical reaction that allows them to be discharged and recharged for repeated use. ${ }^{2}$ The four main types of rechargeable battery are lead-acid, such as those used in traditional vehicles, Ni-Cd, Ni-MH, and LIBs. ${ }^{2}$ Presently, one of the most commercially significant and widely used secondary batteries is the LIB. ${ }^{2}$ Figure 2 shows a comparison of the energy densities of the various common rechargeable batteries. From this plot it is evident that the higher gravimetric energy density and volumetric energy density associated with LIBs is a main factor in their commercial use. Additionally, LIBs generally tend to have a reasonably high cycle life (>1,000 cycles), making them an advantageous choice. $^{2}$ 


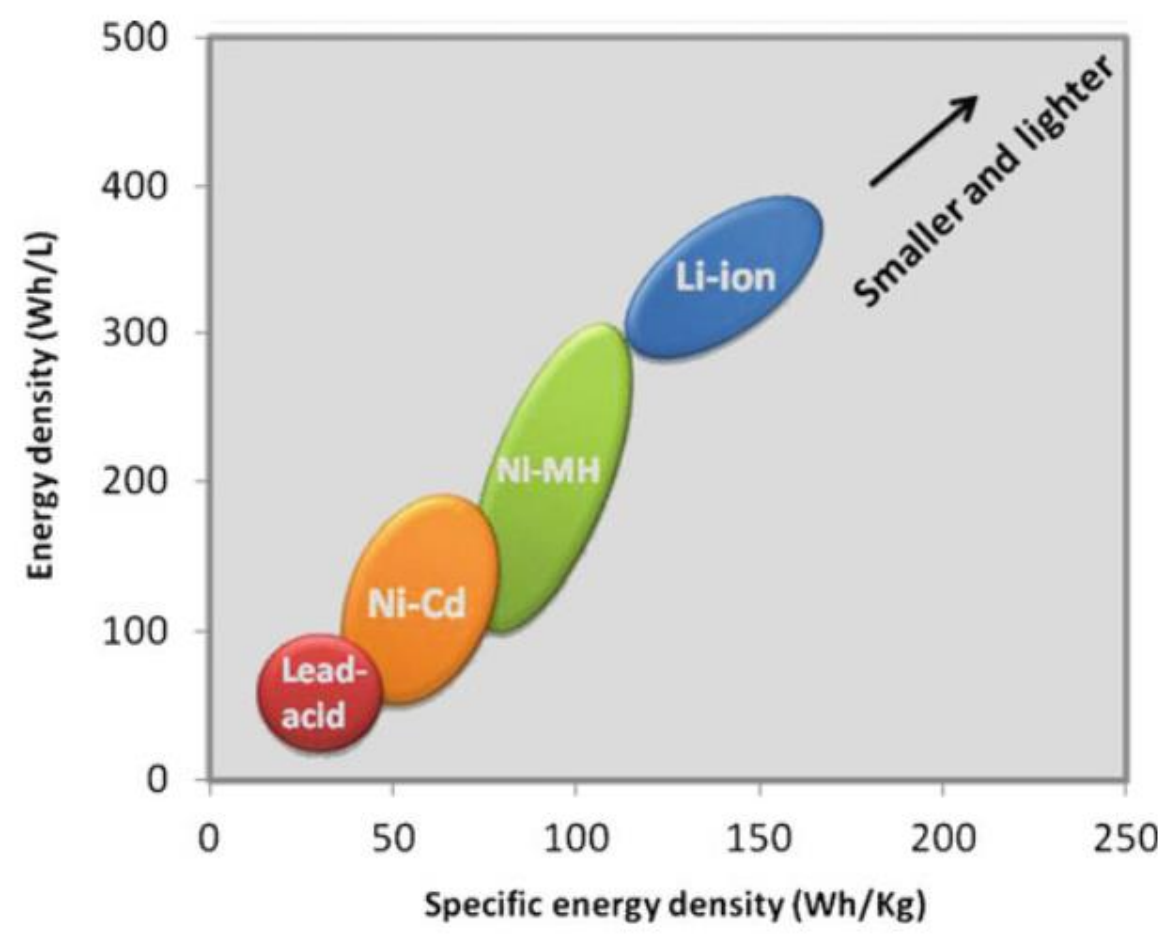

Figure 2: Comparison of energy densities of various secondary batteries. ${ }^{2}$

\subsection{Metal Oxides as Anode Materials}

Metal oxides $\left(\mathrm{M}_{\mathrm{x}} \mathrm{O}_{\mathrm{y}}\right)$ have become an area of research focus in recent years because of their high theoretical capacities as active anode materials. Table 1 shows a comparison of the theoretical capacities of some materials of interest both in the present work and the literature.

Table 1: Selected theoretical specific capacities

\begin{tabular}{cc}
\hline Metal Oxide or Metal & Theoretical Specific Capacity $(\mathbf{m A h} / \mathbf{g})$ \\
\hline $\mathrm{MnO}_{2}$ & $1,233^{2}$ \\
$\mathrm{MnO}$ & $756^{2}$ \\
$\mathrm{NiO}$ & $718^{2}$ \\
$\mathrm{Sn}$ & $993^{2}$ \\
$\mathrm{SnO}_{2}$ & $783^{2}$ \\
\hline
\end{tabular}


Currently, the most widely used anode is made of graphitic carbon. The theoretical capacity reported for carbon is relatively low, about $372 \mathrm{mAh} / \mathrm{g} .{ }^{2,9}$ It is the standard, however, because of its stability as an anode, as it tends to retain its capacity for the lifetime of the battery. ${ }^{2,9}$ Some of the metal oxides of interest in this work, including $\mathrm{MnO}_{2}$ and $\mathrm{SnO}_{2}$ have theoretical capacities of 1,233 and $783 \mathrm{mAh} / \mathrm{g}$ respectively. ${ }^{2}$ The improvement in theoretical capacity, though promising, does not translate directly to a better LIB with use of the pure, bulk oxide material as the active component of a LIB anode, however. This is a result not only of their poor electrical conductivities, but also of the volumetric change that occurs in these materials during their reaction processes with lithium. In the case of $\mathrm{SnO}_{2}$, an expansion of the material during cycling of about $260 \%$ is observed. ${ }^{2}$ Such volumetric change can cause cracking and pulverization of the anode material, loss of contact with the current collector, and eventual failure of the LIB. The reactions for the two aforementioned materials of interest are shown in Equations 1-3.

$$
\begin{gathered}
\mathrm{SnO}_{2}+4 \mathrm{Li}++4 \mathrm{e}^{-} \rightarrow \mathrm{Sn}+2 \mathrm{Li}_{2} \mathrm{O} \\
\mathrm{Sn}+\mathrm{x} \mathrm{Li}^{+}+\mathrm{x} \mathrm{e}^{-} \leftrightarrow \mathrm{Li}_{\mathrm{x}} \mathrm{Sn}(0 \leq \mathrm{x} \leq 4.4) \\
\mathrm{MnO}_{2}+4 \mathrm{Li}^{+}+4 \mathrm{e}^{-} \leftrightarrow \mathrm{Mn}+2 \mathrm{Li}_{2} \mathrm{O}
\end{gathered}
$$

$\mathrm{SnO}_{2}$ undergoes a two-step alloying reaction with lithium to form metallic tin as an intermediate species. Equation 1, for $\mathrm{SnO}_{2}$ is associated with a theoretical specific capacity of $711 \mathrm{mAh} / \mathrm{g}$, and is followed by the reversible reaction listed as Equation 2, which has a theoretical capacity of $993 \mathrm{mAh} / \mathrm{g}$, leading to an overall theoretical capacity of $783 \mathrm{mAh} / \mathrm{g}$ for $\mathrm{SnO}_{2}$. During the first reaction step, $\mathrm{SnO}_{2}$ reacts with lithium to form metallic tin and $\mathrm{Li}_{2} \mathrm{O}$, which is also beneficial to the performance of $\mathrm{SnO}_{2}$ based electrode materials relative to $\mathrm{Sn}$ metal. ${ }^{2}$ This is caused by the buffering matrix formed by the $\mathrm{Li}_{2} \mathrm{O}$ that prevents the 
aggregation of Sn during cycling, which tends to happen in pure tin electrodes. ${ }^{2} \mathrm{MnO}_{2}$, like many transition metal oxides, undergoes a conversion reaction with lithium, as written in Equation 3.

In the traditional literature, with bulk $\mathrm{SnO}_{2}$, the first reaction shown as equation 1 was typically regarded as irreversible. ${ }^{10}$ More recent work, however, has shown that nanoparticulate $\mathrm{SnO}_{2}$ can exhibit some reversibility of the first conversion reaction step leading to an extension of the theoretical capacity to as much as $1490 \mathrm{mAhg}^{-1}{ }^{10}$

\subsection{Nanostructural Confinement of Metal Oxides in Carbon}

Given the promising theoretical capacities of metal oxides and metals for use as anode materials in LIBs, ${ }^{2}$ it is particularly of interest to find a way to mitigate the issues encountered when using these materials in anodes. One method of doing so that has been explored and proven promising is nanostructuring of the materials in question. ${ }^{2,9,11-14}$ The nanostructuring of these materials not only has been shown to improve their resistance to failure due to volumetric change, but also have better performance because of their high surface area to volume ratio. ${ }^{2}$

In addition to nanostructuring the metal oxides, an additional approach to further improving the performance of the materials is by confining these nanostructures within a matrix. ${ }^{15-17}$ The chosen materials that show the most promise are carbon based because graphitic $\mathrm{sp}^{2}$ hybridized carbon, as in graphene and carbon nanotubes (CNTs), has excellent electrical conductivity and mechanical properties. ${ }^{8}$ Agrawal et al. showed that CNTs, specifically, have a significant damping effect, which is of interest to buffer the 
stresses generated due to volumetric change in the metal oxide nanoparticles during reaction with lithium ions in the $\mathrm{LIB} .^{8}$

\subsubsection{Sn@Carbon Nanoparticles in Bamboo-like Hollow Carbon Nanofibers}

Yu et al. explored the use of a carbon structure to confine Sn@carbon nanoparticles for use as a LIB anode. ${ }^{16}$ In this study, the Sn@ carbon particles were encapsulated within hollow carbon nanofibers (CNFs) via electrospinning and pyrolysis to address the issues of volume change and tin particle agglomeration. ${ }^{16}$ Figure 3 shows the TEM images confirming the encapsulation of the Sn@ carbon particles within hollow CNFs. ${ }^{16}$

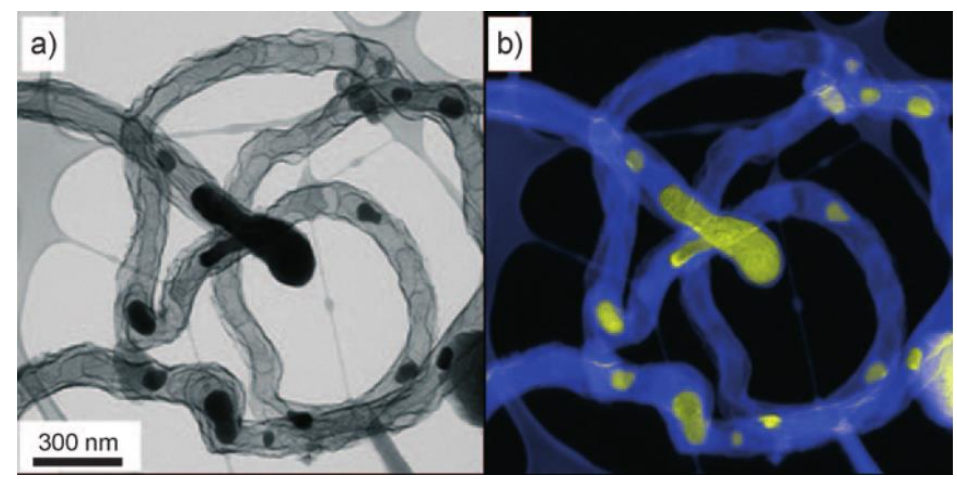

Figure 3: (a) Bright field (BF) zero-loss filtered elastic TEM image of CNFs with Sn@carbon nanoparticles and (b) Elemental mapping confirming the tin and carbon content in the predicted locations. ${ }^{16}$

In this study, it was shown that the composite material for the anode exhibited a reversible capacity, after cycling assembled cells 200 times at $5 \mathrm{C}$, of $737 \mathrm{mAh} / \mathrm{g} .{ }^{16}$ Figure 4 shows the representative cyclic voltammograms (CV) taken with a scan speed of 0.2 $\mathrm{mV} / \mathrm{s}$ and the electrochemical performance for electrode cycled between 0.01 and $3 \mathrm{~V}$ vs. $\mathrm{Li}^{+} / \mathrm{Li}$ with comparison to commercially available nanoscale tin. 

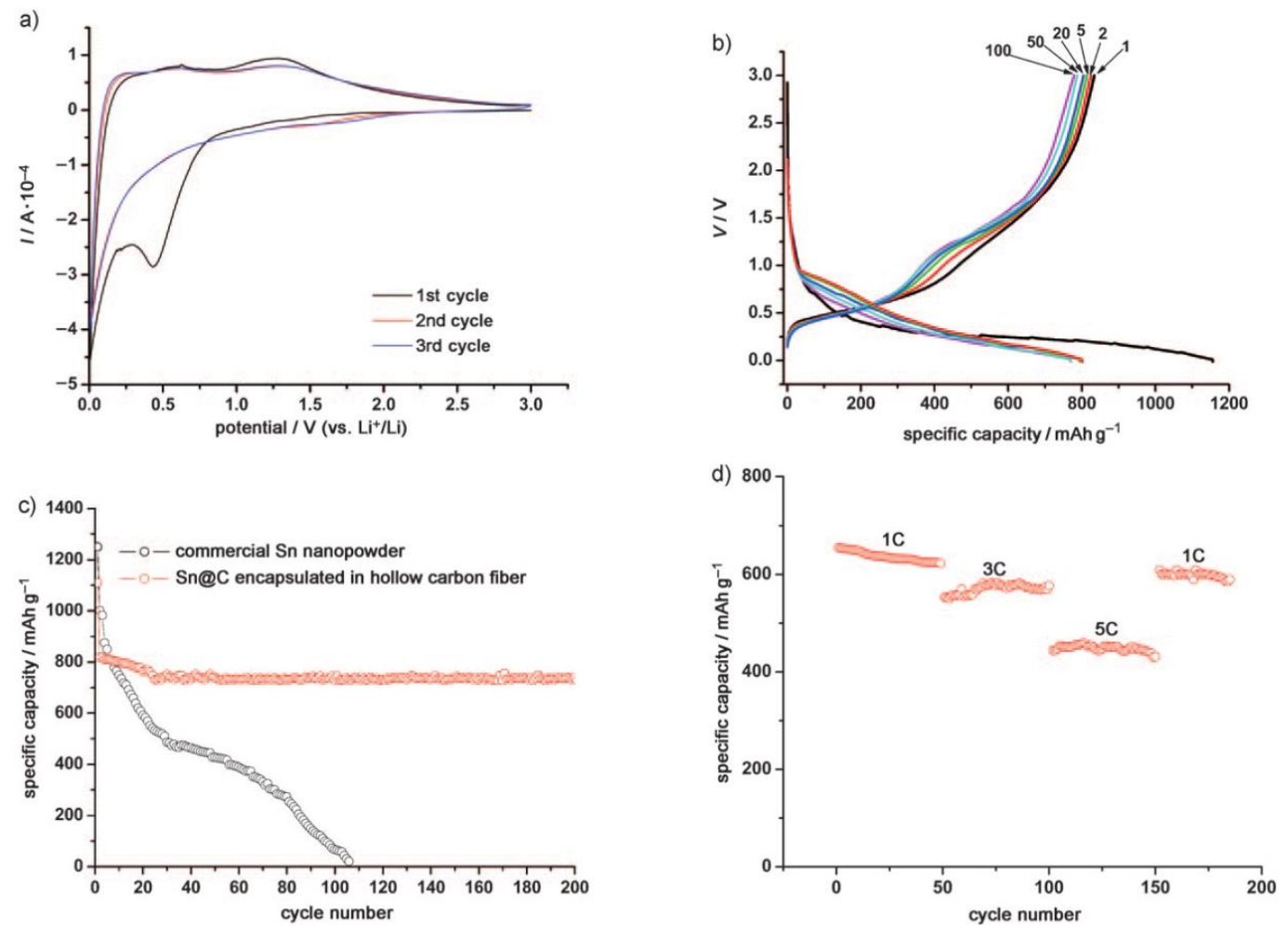

Figure 4: (a) CV for Sn@ carbon encapsulated in CNFs with scan speed of 0.2 mV/s (b-d) Electrochemical performance $\mathrm{vs} . \mathrm{Li}^{+} / \mathrm{Li}$ with cycling between 0.01 and $3 \mathrm{~V} .{ }^{16}$

\subsubsection{Comparison of $\mathrm{SnO}_{2}$ Based Anodes with Various Nanostructured Carbons}

Guo et al. conducted work on monodisperse $\mathrm{SnO}_{2}$ particles on reduced graphene oxide (RGO) platelets and compared these results with those of a variety of tin oxide and carbon structured anode material work. ${ }^{10}$ Table 2 shows a summary of the work compared by Guo et al. in their review, indicating the current rates at which various studies tested their materials of interest, the observed discharge capacities reported, and their retention of capacity with cycling (indicating number of cycles used). ${ }^{10}$ From the work presented by Guo et al., the monodisperse $\mathrm{SnO}_{2}$ on $\mathrm{RGO}$ had the best discharge specific capacity of $1057 \mathrm{mAh} / \mathrm{g}$ in the second cycle and best capacity retention of $1036 \mathrm{mAh} / \mathrm{g}$ after $400 \mathrm{cycles}$ when tested at a current rate of $500 \mathrm{mAh} / \mathrm{g}$. 
Table 2: Comparison of various $\mathrm{SnO}_{2}$ and carbon composite electrode capacities for LIB anodes

\begin{tabular}{|c|c|c|c|}
\hline Sample & $\begin{array}{c}\text { Current } \\
\text { Rate } \\
(m A / g)\end{array}$ & $\begin{array}{c}\text { Discharge } \\
\text { Capacity }(m A h / g)\end{array}$ & $\begin{array}{c}\text { Capacity Retention } \\
(m A h / g) /(\text { cycles })\end{array}$ \\
\hline Monodisperse $\mathrm{SnO}_{2}$ on $\mathrm{RGO}$ & 500 & 1057 ( $2^{\text {nd }}$ cycle $)$ & $1036 / 400$ \\
\hline $\mathrm{SnO}_{2} /$ Graphene & 100 & 931 & $718 / 200$ \\
\hline $\mathrm{SnO}_{2}$ nanosheets & 156 & 762 & $534 / 50$ \\
\hline $\mathrm{SnO}_{2} /$ Graphene & 50 & 1080 & $649 / 30$ \\
\hline $\mathrm{SnO}_{2} / \mathrm{CNF}$ & 100 & & $383 / 30$ \\
\hline $\mathrm{SnO}_{2} / \mathrm{CNT}$ & 200 & & $497 / 300$ \\
\hline
\end{tabular}

\subsubsection{Nanoconfined $\mathrm{MnO}_{2}$ in CNTs}

Interest in the nanoconfinement of metal oxides in carbon channels stems largely from the work of Chmiola et al. who used a carbon structure into which nanometer-scale pores were etched and subsequently filled with $\mathrm{MnO}_{2}$ particles. ${ }^{18}$ This work assessed the capacitance of such materials and found that gaps between the carbon structure and metal oxide particle smaller than $1.5 \mathrm{~nm}$ can contribute to charge storage far more than was previously thought. ${ }^{18}$ This improved charge storage is thought to stem from a pseudocapacitive effect, which could, in turn, be observed with confinement of particles in the inner channels of carbon nanotubes.

The groundwork and proof-of-concept for the encapsulation of particulate metal oxides within carbon nanotubes, specifically, came from the work of Chen et al. in the nanoconfinement of $\mathrm{MnO}_{2}$ nanoparticles within CNTs for use in a capacitor application. ${ }^{15}$ In this work, a reliable method was devised for the confinement of manganese dioxide nanoparticles within multiwalled (MW) CNTs and an improvement was shown for the material of interest, which contained the nanoparticles within the CNTs versus the particles outside CNTs, just the CNTs, or just the $\mathrm{MnO}_{2} \cdot{ }^{15}$ Figure 5 shows the TEM micrographs 
indicating the presence of the $\mathrm{MnO}_{2}$ particles within the CNTs as well as the comparison with the samples made that had $\mathrm{MnO}_{2}$ outside the CNTs. ${ }^{15}$

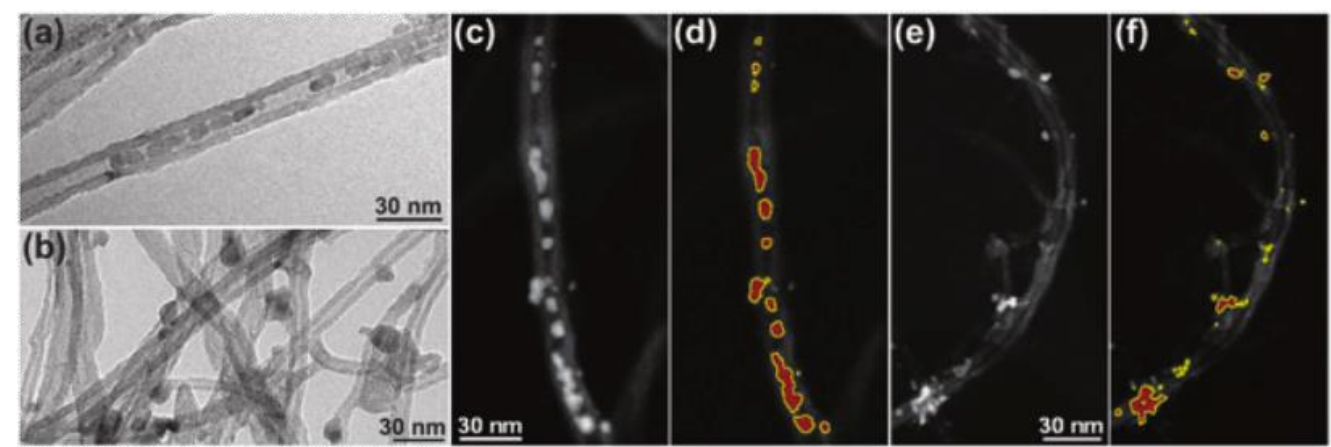

Figure 5: (a) BF TEM micrograph of $\mathrm{MnO}_{2}$ confined within CNT, (b) $\mathrm{MnO}_{2}$ outside CNT, (c-f) High angle area diffraction images and elemental analysis showing confinement of $\mathrm{MnO}_{2}$ within $\mathrm{CNTs}^{15}$

The study showed improved reversibility and capacity of the composite material created in this study. ${ }^{15}$ Additionally, the procedure developed was able to reliably achieve up to $20 \%$ mass loading of the $\mathrm{MnO}_{2}$ nanoparticles within the MW CNTs. ${ }^{15}$ Figure 6 shows the comparison of the specific capacitance of the various samples tested, cyclic voltammetry, and tabulated data. ${ }^{15}$ From these results, it was found that the $\mathrm{MnO}_{2}$ confined within the CNTs gave a specific capacitance as high as $225 \mathrm{~F} / \mathrm{g}$ and when normalized by $\mathrm{MnO}_{2}$ gave a specific capacitance of $1250 \mathrm{~F} / \mathrm{g} .{ }^{15}$

In this study, electrostatic spray deposition (ESD) was used to form a thin film of the electrode materials of interest on a substrate that was used as the current collector for subsequent testing of the electrochemical performance of these anodes. ${ }^{15}$ This technique is of interest for use because of its versatility for film deposition of many different materials and morphologies, as well as its ability to allow for simultaneous heat treatment, if needed, up to moderate temperatures., ${ }^{9,15,19-21}$ 

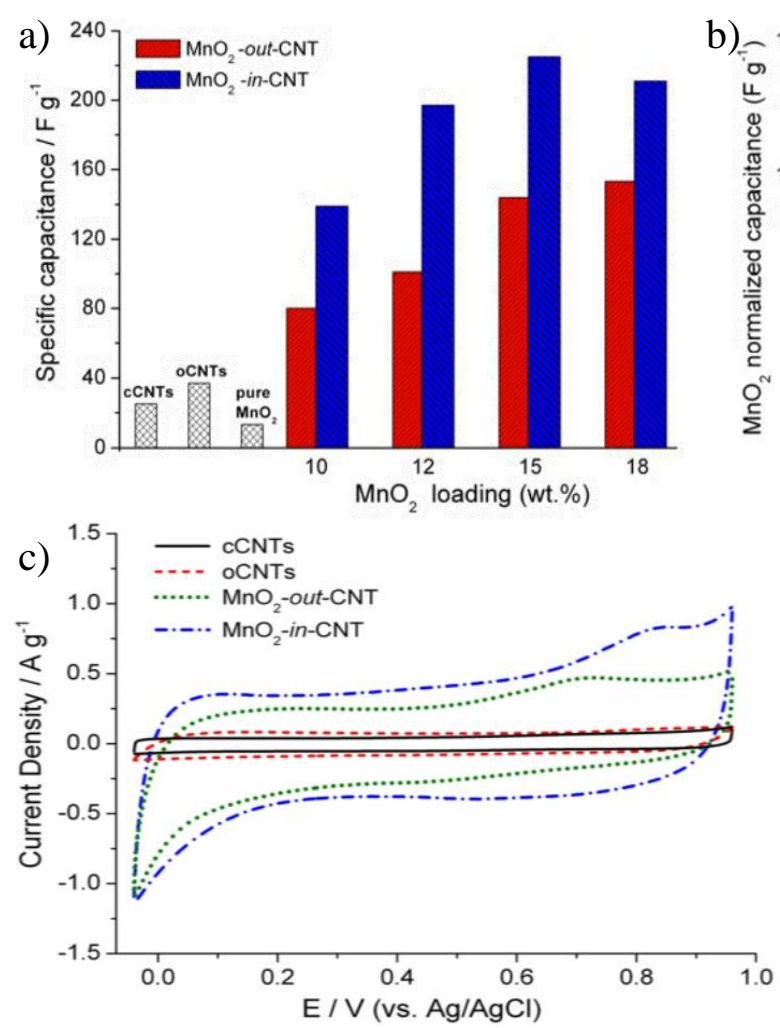

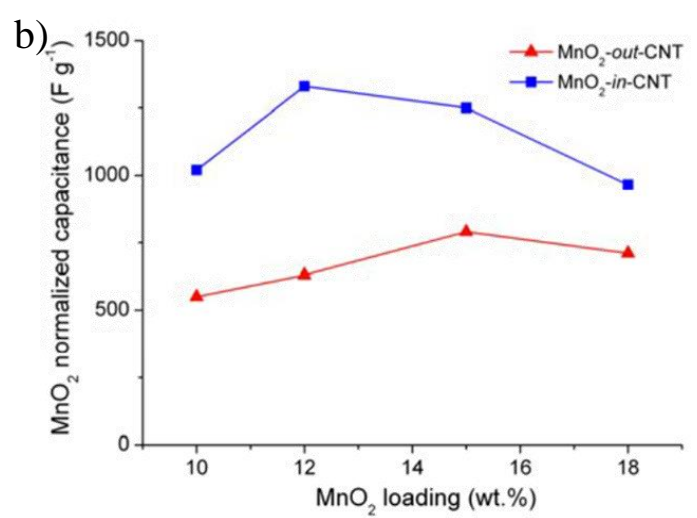

d)

\begin{tabular}{ccc}
\hline Sample & $\begin{array}{c}\text { Specific capacitance } \\
\text { obtained by CV curves } \\
\left(\mathrm{F} \mathrm{g}^{-1}\right)^{\mathrm{a}}\end{array}$ & $\begin{array}{c}\text { Specific capacitance } \\
\text { normalized by } \mathrm{MnO}_{2} \\
\left(\mathrm{~F} \mathrm{~g}^{-1}\right)\end{array}$ \\
\hline $\mathrm{cCNTs}$ & 25 & - \\
$0 \mathrm{CNTs}$ & 37 & - \\
$\mathrm{MnO}_{2}$ & 13 & 13 \\
$\mathrm{MnO}_{2}$-out-CNT & 144 & $790^{\mathrm{b}}$ \\
$\mathrm{MnO}_{2}-$ in -CNT & 225 & $1250^{\mathrm{c}}$
\end{tabular}

${ }^{a}$ Calculated by integrating area of $\mathrm{CV}$ curves. ${ }^{b}$ Based on weight percentage of $\mathrm{MnO}_{2}$ by subtracting the specific capacitance of blank cCNTs. ${ }^{\mathrm{C}}$ Based on weight percentage of $\mathrm{MnO}_{2}$ by subtracting the specific capacitance of blank oCNTs.

Figure 6: (a) Specific capacitance comparison, (b) comparison of normalized specific capacitance between $\mathrm{MnO}_{2}$ outside vs. inside CNTs for composite anodes, (c) $\mathrm{CV}$ comparing $\mathrm{CNTs}_{\text {without }} \mathrm{MnO}_{2}$ to CNTs with $\mathrm{MnO}_{2}$ both outside and inside, (d) Tabulated values of specific capacitance and $\mathrm{MnO}_{2}$ normalized specific capacitance. ${ }^{15}$ 


\section{CHAPTER III}

\section{EXPERIMENTAL TECHNIQUES AND METHODS}

This section details the experimental techniques used to prepare the active material of the anodes of interest for subsequent study as well as the analytical techniques used to characterize these materials and the electrochemical testing done to assess their performance for LIB anode use. The chapter also gives an overview of the process of electrostatic spray deposition (ESD), the method chosen to deposit the active material as a thin film onto a substrate that would serve as the current collector for the LIB anodes.

\subsection{Material Preparation}

Preparation of the active material began with the acid treatment of multi-walled carbon nanotubes (MWCNTs) and subsequent filling with a precursor for the tin oxide. These procedures were based off those used by Chen et al. for a similar configuration that contained manganese oxide rather than tin oxide. ${ }^{15}$ The MWCNTs were purchased from Cheap Tubes Inc., made via a chemical vapor deposition (CVD) process and purified by the vendor prior to sale. The outer diameters of the CNTs were 8-15 nm and the inner diameters were $3-5 \mathrm{~nm}$. The purity was listed as $>95 \%$ and the tubes were $10-50 \mu \mathrm{m}$ in length. They had a specific surface area of $233 \mathrm{~m}^{2} / \mathrm{g}$, an electrical conductivity greater than $100 \mathrm{~S} / \mathrm{cm}$, a bulk density of $0.15 \mathrm{~g} / \mathrm{cm}^{3}$ and a true density of $\sim 2.1 \mathrm{~g} / \mathrm{cm}^{3}$. For the desired nanoparticulate-filled MWCNTs to be produced, the CNTs first had to be treated with acid to open their ends, cut the tubes to a shorter length of $\sim 0.2-1 \mu \mathrm{m}$, and remove any possible metal catalyst residue. The acid treatment was carried out in refluxing apparatus with a condenser tower attached to a round bottom flask containing the MWCNTs and sufficient 
nitric acid $\left(\mathrm{HNO}_{3}, 70 \%\right)$ to completely cover and immerse the CNTs $(\sim 50 \mathrm{~mL})$. The round bottom flask was immersed in a silicone oil bath to maintain even temperature distribution throughout the flask and the oil bath was raised to $140^{\circ} \mathrm{C}$ and held at this temperature for 14 hours.

After the acid treatment of the CNTs was completed, the insertion of the tin oxide $\left(\mathrm{SnO}_{2}\right)$ nanoparticles had to be carried out to obtain the final active material for the desired LIB anodes. In order to obtain the $\mathrm{SnO}_{2}$, tin (IV) acetate (Sigma Aldrich) was used as a precursor for subsequent oxidation to obtain the finished product. The tin (IV) acetate was dissolved in ethanol $(50 \% \mathrm{w} / \mathrm{w})$ and the acid treated CNTs were introduced to the mixture to obtain the desired weight ratio of $\mathrm{SnO}_{2}$ to $\mathrm{CNT}(10 \%, 20 \%, 25 \%$, or $30 \%)$ with stoichiometric calculations used to obtain the correct output of $\mathrm{SnO}_{2}$ based on the quantity of tin (IV) acetate required. The weight fractions selected for this study were based on the values that would give a comparable molar ratio to those values used for the $\mathrm{MnO}_{2}$ study by Chen et al. ${ }^{15}$ The capillary forces of the CNTs were used to introduce the tin (IV) acetate precursor solution into the inner channels and the process was further aided with stirring and subsequent ultrasonic treatment for 2 hours. The resultant mixture was slowly dried at room temperature and the dried powder was heat-treated in air in a box furnace at $300^{\circ} \mathrm{C}$ for four hours to allow oxidation of the tin (IV) acetate into $\mathrm{SnO}_{2}$. Throughout this text, the samples prepared this way will be referred to as $\mathrm{SnO}_{2}$-in-CNT. The control group samples that were used to compare confined vs. unconfined $\mathrm{SnO}_{2}$ are denoted $\mathrm{SnO}_{2}$-out-CNT.

\subsection{Electrostatic Spray Deposition (ESD)}


ESD is a thin film deposition method, originally detailed by J. Zeleny in 1914, which uses a voltage applied to the source of a solution and grounding of the substrate, on which the material is to be deposited, to atomize the solution via the applied field and draw it across a gap to create the final film. ${ }^{22}$ Here, a precursor solution is loaded into a syringe and then a syringe pump is used to dispense the solution at a constant flow rate through a syringe needle to which the voltage source is connected. The substrate is heated to a sufficiently high temperature to allow the evaporation of the solvent. The applied field serves to charge the surface of the droplet that forms at the tip of the syringe needle that is typically used in this procedure and it is this charging that overcomes the surface tension and causes atomization. The advantages of using this technique are numerous. It is inexpensive, efficient, simple, does not need to be carried out under vacuum, and can be used to create a variety of different microstructures. This is made possible by the many parameters that can be adjusted for the deposition of a film. Film deposition parameters using ESD include: substrate temperature, applied voltage, precursor solution flow rate, deposition time, needle-to-substrate distance, and precursor solution composition. Fine tuning and optimizing these parameters can allow for the creation of many different microstructures of the films. ${ }^{9,19-21}$ Figure 7 shows a schematic representation of the process of ESD and a photograph of the testing setup during use. The photograph shows the conical geometry of the atomized spray during thin film deposition. 
(a)

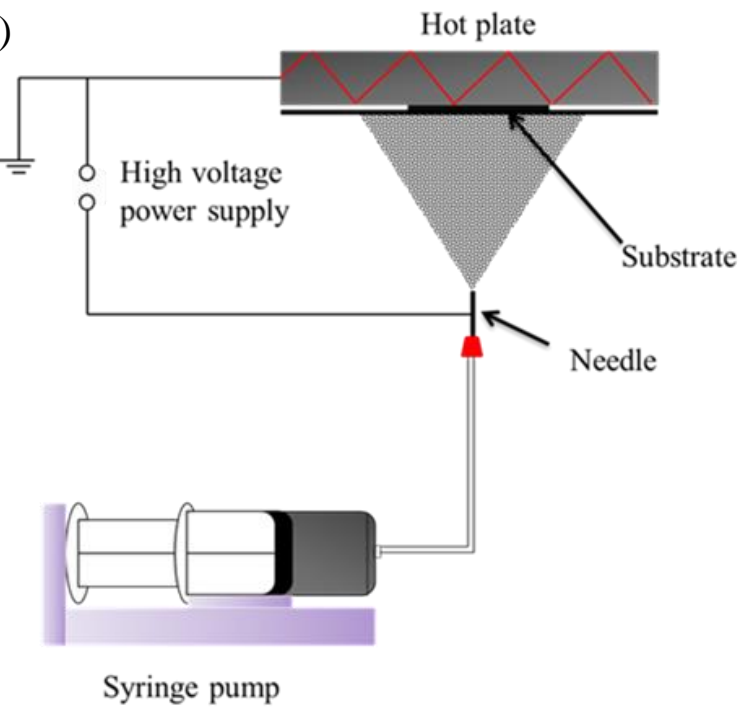

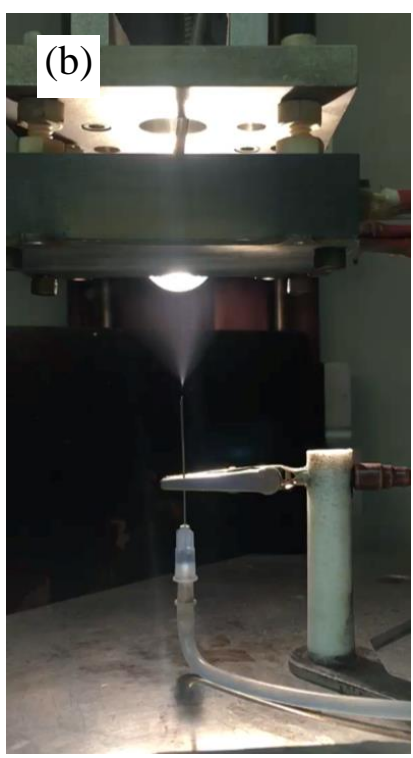

Figure 7: (a) Schematic representation of the ESD process and (b) photograph of setup.

The precursor solution used for ESD contained the $\mathrm{SnO}_{2}$-in-CNT dissolved in a $60 \%$ ethanol, $40 \% 1,2$ propanediol solvent mixture that was found to be the optimum for deposition of the active material of interest. Prior to use for ESD, the precursor solution was stirred and mixed ultrasonically for 1-2 hours until immediately prior to beginning ESD. For these tests, the parameters used for film deposition were a flow rate of $\sim 4$ $\mathrm{mL} /$ hour and a voltage of $5-8 \mathrm{kV}$. The substrate was always heated to $300^{\circ} \mathrm{C}$ using a thermocouple to verify temperature. ESD is carried out in air at atmospheric pressure.

\subsection{Structural and Morphological Characterization}

In order to verify that the desired composition and structure of the active material of interest were obtained and that all the control groups were controlling for the correct parameters, several analytical techniques were used. The three main characterization methods used were x-ray diffraction (XRD), scanning electron microscopy (SEM), and 
transmission electron microscopy (TEM), each of which served an important function in verification of the materials of interest.

\subsubsection{X-Ray Diffraction (XRD)}

$\mathrm{X}$-ray diffraction is a technique that uses an incident $\mathrm{x}$-ray beam to study the crystallographic structure of materials and identify material composition. For this work, XRD data was obtained using a Siemens D-5000 diffractometer with $\mathrm{Cu} K \alpha$ radiation $(\lambda=$ $1.542 \AA$ ). Specifically, in this work this technique was used to assess the efficacy of the heat treatment in the experimental procedure in producing the desired $\mathrm{SnO}_{2}$ in both the relevant control and experimental groups. Samples for XRD were collected as powder after deposition with ESD onto an aluminum plate without the nickel foam substrate.

\subsubsection{Scanning Electron Microscopy (SEM)}

To characterize the microstructure and morphology of the thin films deposited on our substrates via ESD, SEM was employed. SEM images were taken with a JEOL JSM6330 field-emission scanning electron microscope (FESEM) working at $15.0 \mathrm{kV}$. The SEM is equipped with an energy dispersive x-ray spectrometer (EDS), which is used to identify the elemental composition of points or areas in an SEM image.

\subsubsection{Transmission Electron Microscopy (TEM)}

TEM is a powerful tool for gaining very high-resolution images of materials'

microstructure and nanostructure, often even down to the level of atomic resolution for high resolution TEM (HRTEM). TEM imaging was carried out on a Phillips CM-200 200 
kV Transmission Electron Microscope (TEM) with Energy Dispersive Spectroscopy (EDS). TEM was primarily used in this work to confirm confinement of $\mathrm{SnO}_{2}$ within the MWCNTs and compare the control samples to the experimental samples to ensure that particles were unconfined in the $\mathrm{SnO}_{2}$-out-CNT samples.

\subsection{Assembly of Cells}

For the anode material of interest to be properly tested electrochemically, half cells were assembled containing the deposited film on the nickel foam substrate with lithium metal serving as the lithium source for testing and cycling of the cells. Cell assembly was carried out in a glove box filled with argon gas and maintaining both the atmospheric oxygen and water levels at less than $1 \mathrm{ppm}$. The cells were assembled as coin cells in CR 2032 packaging. All half-cells contained a thin, permeable membrane polymer-based separator between the nickel foam substrate with active material and the lithium metal. All assembled cells used the same electrolyte, lithium hexafluorophosphate $\left(\mathrm{LiPF}_{6}\right.$, Sigma Aldrich, battery grade, $\geq 99 \%$ trace metals basis), for consistency and comparability of results.

\subsection{Electrochemical Performance Testing}

In order to compare the control and experimental group cells, various tests were carried out on the assembled half-cells. These tests include cyclic voltammetry (CV), galvanostatic charge-discharge testing, and rate capability testing. All electrochemical testing of the assembled coin cells was carried out after a delay of about 24-48 hours after cell assembly to give an adequate rest time for stabilization. 
Cyclic voltammetry (CV) is useful to determine the reversibility of a reaction or reactions in the process of cycling an electrochemical cell or half-cell. It is carried out for a specified number of cycles within a fixed voltage window at a specified scan rate $(\mathrm{mV} / \mathrm{s})$ and measures the current response from electron transfer processes. Typically the first cycle differs most greatly from the subsequent cycles in any electrochemical test because of some irreversible capacity loss occurring after the first cycle. After this first cycle, most cells tend to stabilize. CV was carried out using a BioLogic VMP3 electrochemical testing setup. CV was carried out at rates of $0.1,0.2,0.5,1.0$, and $2.0 \mathrm{mVs}^{-1}$.

Galvanostatic charge-discharge tests are carried out by discharging and charging the half-cells for the desired number of cycles to determine overall trends in capacity retention, loss, or gain with use. A fixed current is chosen for charge and discharge of the cells and in this study discharging and charging were carried out for up to 200 cycles per half-cell. Rate capability testing operates similarly to the charge-discharge testing, but rather than test a half-cell for 100 cycles at one fixed current, different current values are tested for a number of cycles on a single cell to compare the capacity of the cell at different rates. All rate capability and charge-discharge tests were carried out on a Neware BTS-610 battery testing apparatus.

In order to determine the specific capacity of the active material of interest for all half-cells, masses were taken of the substrate before and after ESD was carried out to determine the mass deposited. That measured change in mass was used for all specific capacity calculations. All electrochemical testing was done on all half-cells at room temperature, $\sim 25^{\circ} \mathrm{C}$. 


\subsection{Experiment Design and Controls}

In order to accurately analyze the results of electrochemical performance obtained from testing the experimental group of interest, the study was designed to include necessary control groups for comparison. Specifically, this work hypothesized that the confinement of $\mathrm{SnO}_{2}$ nanoparticles within the inner channels of MWCNTs would result in cells with improved electrochemical performance. This performance, therefore, had to be compared versus $\mathrm{SnO}_{2}$ alone, MWCNTs alone, and unconfined $\mathrm{SnO}_{2}$, referred to as $\mathrm{SnO}_{2}$-out-CNT to differentiate from the confined samples. Therefore, $\mathrm{SnO}_{2}$ samples were prepared by mixing the tin (IV) acetate precursor with closed MWCNTs, drying and heat treating via the same process detailed in section 3.1, and depositing this active material via ESD similarly onto a $\mathrm{Ni}$ foam substrate. Samples containing $\mathrm{SnO}_{2}$ alone as the active material were prepared with ESD carried out using the tin (IV) acetate precursor dissolved in the same ratio combination of ethanol and 1,2 propanediol. The nickel foam substrate onto which the tin (IV) acetate was deposited was heated to $300^{\circ} \mathrm{C}$, above the oxidation temperature of $270^{\circ} \mathrm{C}^{17}$, and carried out in air. Full oxidation of tin (IV) acetate to $\mathrm{SnO}_{2}$ was confirmed using XRD and the results are shown in Chapter IV. 


\section{CHAPTER IV}

\section{RESULTS AND DISCUSSION}

\subsection{Characterization Results}

\subsubsection{X-ray Diffraction (XRD)}

X-ray diffraction was used in this study with the primary objective of verifying that the tin (IV) acetate that was used as a precursor material for the $\mathrm{SnO}_{2}$ in both the control and experimental group samples had oxidized as expected to give the $\mathrm{SnO}_{2}$. Therefore, for each group some powder was taken and XRD was carried out to identify the composition. Figure 8 shows the comparison of the XRD patterns for $\mathrm{SnO}_{2}$ alone, $\mathrm{SnO}_{2}$-in-CNT, $\mathrm{SnO}_{2}$ out-CNT, and CNTs alone. The XRD results showed that the $\mathrm{SnO}_{2}$ alone sample was indeed oxidized as desired from the tin (IV) acetate precursor, as were the experimental and control groups with $\mathrm{SnO}_{2}$, thus validating the heat treatment step of the experimental procedure. that there was very little difference between the $\mathrm{SnO}_{2}$-in-CNT and the $\mathrm{SnO}_{2}$ out-CNT samples, as expected. The XRD pattern for the MWCNTs was typical and comparable to other XRD carried out on CNTs in prior literature. ${ }^{23}$ The patterns show some overlap between the main CNT peak and the $\mathrm{SnO}_{2}$ (110) peak. Additionally, the main contribution to the XRD patterns of the composite samples was the $\mathrm{SnO}_{2}$, which can be attributed to the crystallinity of this material. 


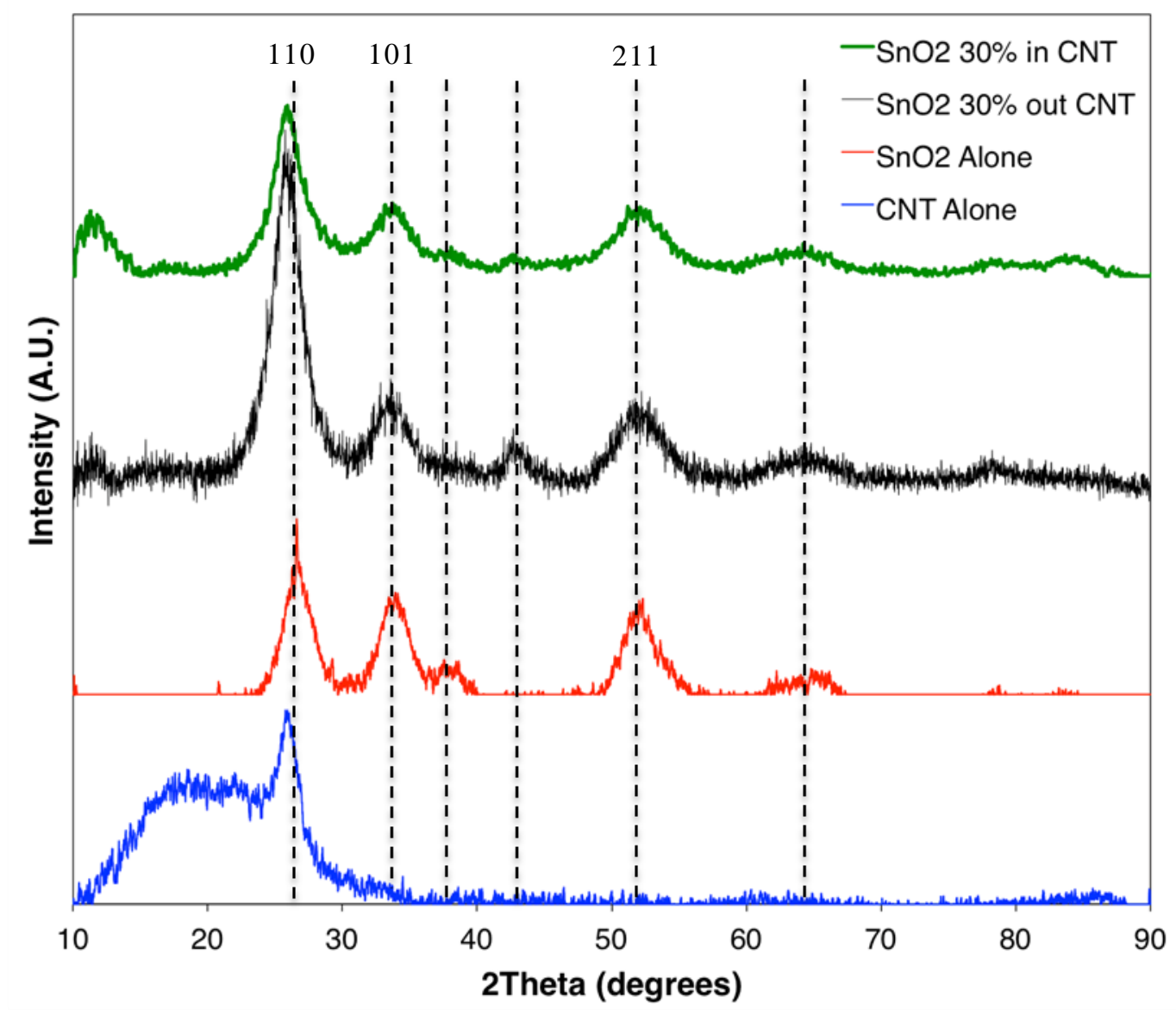

Figure 8: XRD data for confined, unconfined, $\mathrm{SnO}_{2}$ alone, and CNT alone samples.

\subsubsection{Scanning Electron Microscopy (SEM)}

SEM was utilized to verify the microstructure of the deposited thin films onto the nickel foam current collector (substrate) to ensure that the deposited film was even and sufficiently porous to allow improved $\mathrm{Li}^{+}$ion diffusion into the active anode material. Figure 9 (a) shows an SEM image with 95x magnification where the larger structure of the porous nickel foam can be seen with an even thin film coating deposited on all visible surfaces. Figure 9 (b) at 550x magnification gives a more detailed image of one section of the nickel foam, highlighting both the porosity of the deposited film and its evenness at a $10 \mu \mathrm{m}$ resolution. In Figure 9 (c), an enlarged view of the morphology is shown at a 
magnification of 2,300x. The fourth SEM image, Figure 9 (d) was taken at 75,000x magnification, showing a representative region of the deposited film. In (d) individual CNTs are visible without any external agglomerated $\mathrm{SnO}_{2}$, further supporting confinement of the $\mathrm{SnO}_{2}$ particles within the CNTs.

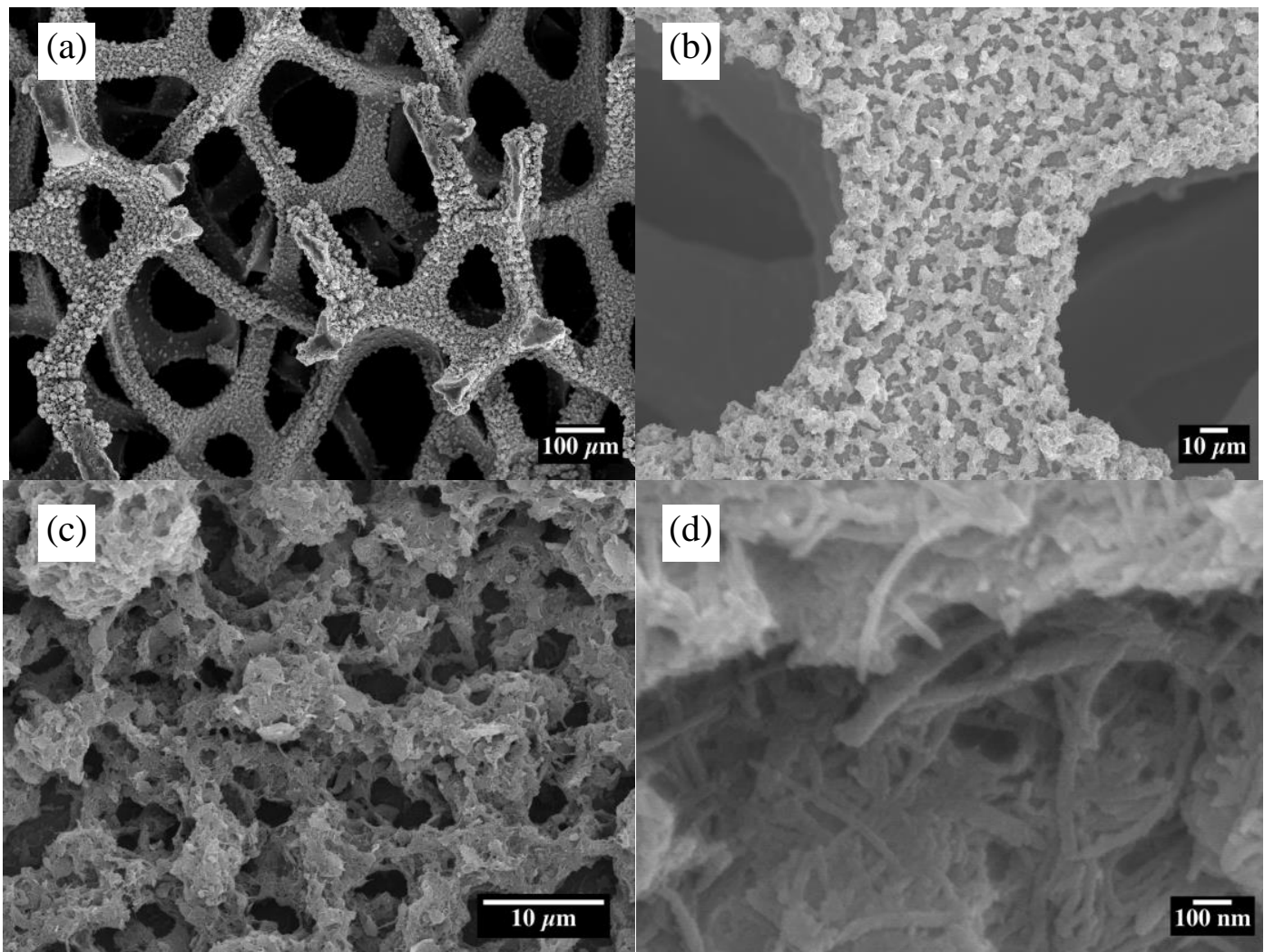

Figure 9: SEM of $\mathrm{SnO}_{2}$-in-CNT sample with (a) 97x, (b) 550x, (c) 2,300x and (d) 75,000x magnifications

\subsubsection{Transmission Electron Microscopy (TEM)}

The purpose of TEM for this study was to confirm that confinement of $\mathrm{SnO}_{2}$ within the CNTs was successfully achieved. Figure 10 shows TEM images of $\mathrm{SnO}_{2}$-in-CNT sample where CNTs with $\mathrm{SnO}_{2}$ nanoparticle are visible. In the TEM images, the MWCNTs were identified by the layered structure of the wall and the inner and outer diameter sizing being in keeping with the expected diameters from the manufacturer's specifications (8-15 
nm outer diameter, 3-5 nm inner diameter. The $\mathrm{SnO}_{2}$ nanoparticles are the darker spots within the CNTs visible in Figure 10. Figure 10 (a) and (b) show a magnified view of the individual carbon nanotube and $\mathrm{SnO}_{2}$ particle with visible interplanar spacing. Figure 10 (c) shows the profile taken of the $\mathrm{SnO}_{2}$ particle to confirm that the d-spacing was inkeeping with the predicted value for $\mathrm{SnO}_{2}$, which was confirmed. Additional images with more carbon nanotubes and more $\mathrm{SnO}_{2}$ particles, showing particulate confinement, are shown in (d) and (e). 

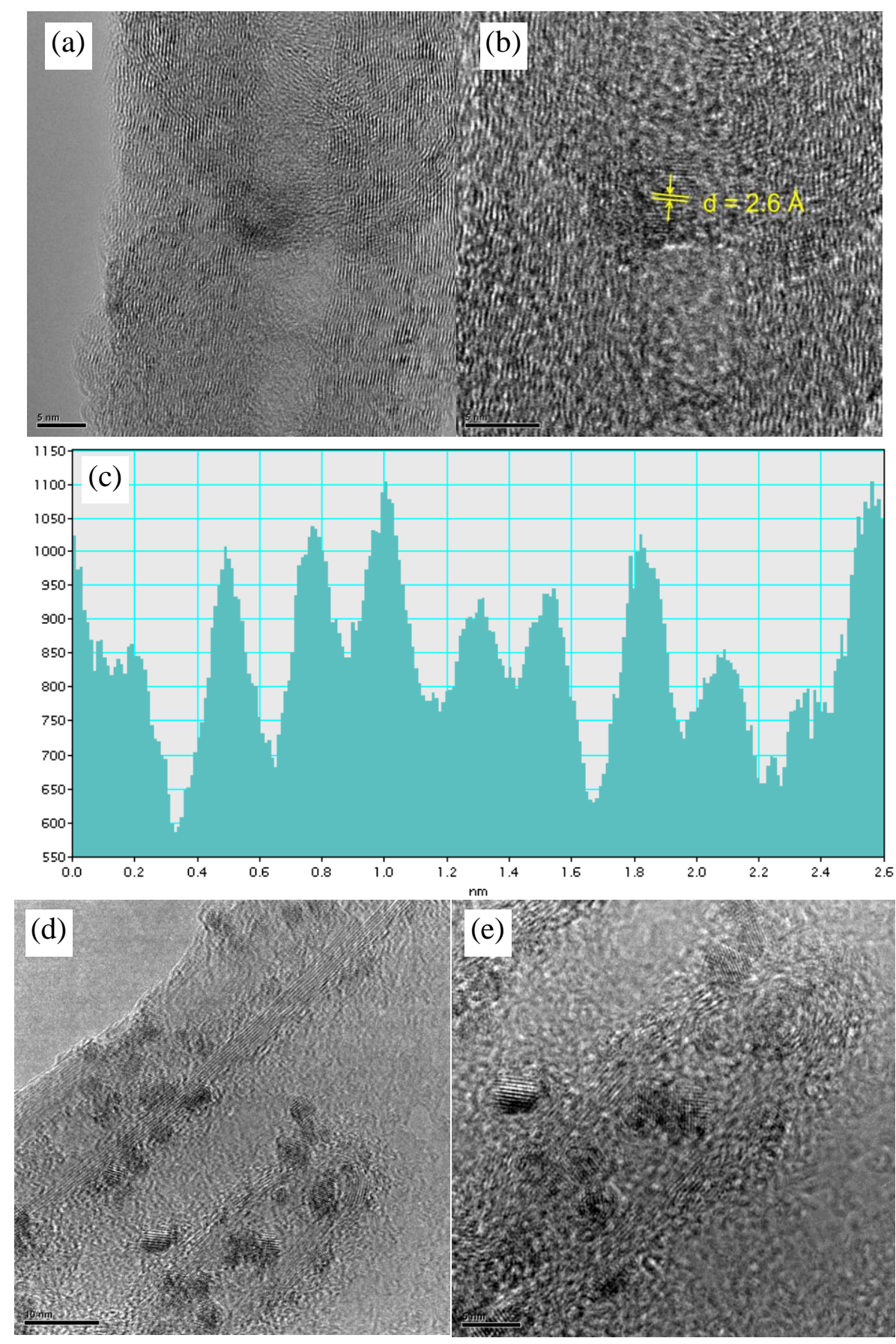

Figure 10: (a) and (b) TEM images showing an individual carbon nanotube, vertically oriented, with a tin oxide nanoparticle showing clear confinement with identification of the $d$-spacing between atomic planes (c) Profile of interplanar spacing for $\mathrm{d}=\mathbf{2 . 6} \AA$ corresponding to $\mathrm{SnO}_{2}$. (d), and (e), showing confinement of $\mathrm{SnO}_{2}$ particles within CNTs. 


\subsection{Electrochemical Results}

In Figure 11 the results of cyclic voltammetry taken at a scan rate of $0.2 \mathrm{mVs}-1$ for the third cycle of the various sample groups are shown. For the tin oxide alone control sample, characteristic oxidation and reduction peaks are visible. The peak between 0.1 and $0.5 \mathrm{~V}$ corresponds to $\mathrm{Li}$ ions alloying with the metallic $\mathrm{Sn}$ that is a product of the first reaction step. The peak at $\sim 1.0 \mathrm{~V}$ is attributed to the SEI formation and the peak at $1.35 \mathrm{~V}$ corresponds to the reduction of $\mathrm{SnO} 2$ to metallic $\mathrm{Sn}$ in the first reaction step. The reverse reaction is represented by the peak at about $1.2 \mathrm{~V}$, which is visible in the $\mathrm{SnO} 2$ alone, and the $20 \%$ and $30 \%$ SnO2-in-CNT samples. Finally, the de-alloying process of Li leaving the $\mathrm{Li}_{\mathrm{x}} \mathrm{Sn}$ compound is visible at about $0.55 \mathrm{~V}$. The current response seen for CNTs alone was very small, as was that of the unconfined sample, which does not show the redox peaks as noticeably as the confined samples. Though the $\mathrm{SnO}_{2}$ showed a large current response for the first few cycles, with subsequent cycles this response deteriorated greatly, resulting in high instability of the half-cell with cycling over time. 


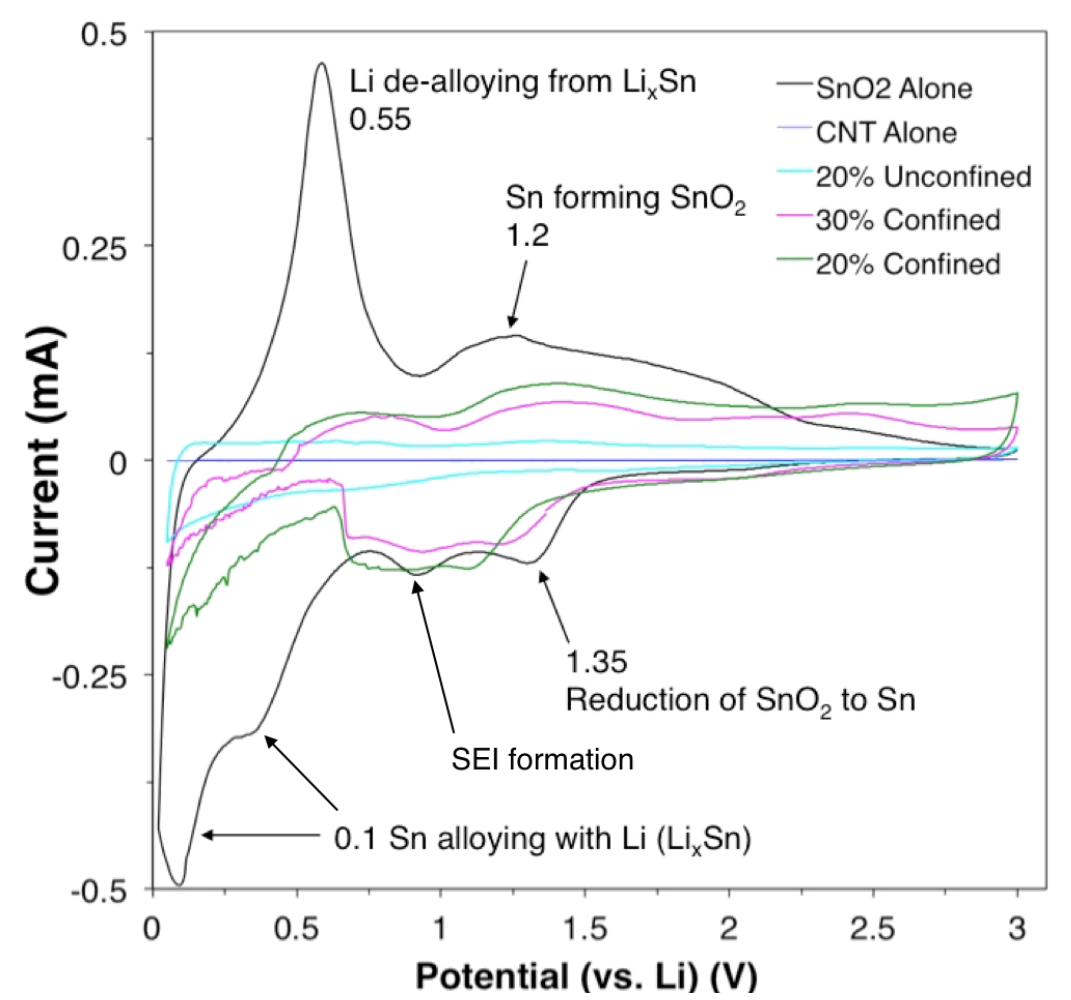

Figure 11: Cyclic voltammetry curves for experimental and control group samples

Figure 12 shows the galvanostatic charge-discharge curves for $20 \% \mathrm{SnO}_{2}$-in-CNT active material half-cell sample cycled at a rate of $100 \mathrm{mAg}^{-1}$ through cycle 150 of discharging then charging the cell. With the first cycle, the cell shows the greatest value with the first discharge for specific capacity, with its maximum value falling at about 1300 $\mathrm{mAhg}^{-1}$. For the discharge for cycle two, the specific capacity maximum fell at just under $700 \mathrm{mAhg}^{-1}$, about half the original value. This trend continues through cycle 10, however by cycle 40 the specific capacities steadily increased. In fact, the highest specific capacity measured on the charge side was seen with the charge step for cycle 150. The discharge cycles showed a gradual increase in the maximum measured specific capacity continuing through cycle 150 for which the value was greater than $900 \mathrm{mAhg}^{-1}$. Such trends are sometime seen in metal oxide anode materials and attributed to an electrochemical milling effect in which the particle size becomes reduced with cycling of the LIB. ${ }^{24,25}$ A decrease 
in the particle size then, consequently, results in an increased surface area of the metal oxide particles exposing a larger surface for reaction with $\mathrm{Li}^{+}$ions. This, in turn, is thought to be the cause of the gradual increase in specific capacity with cycling.

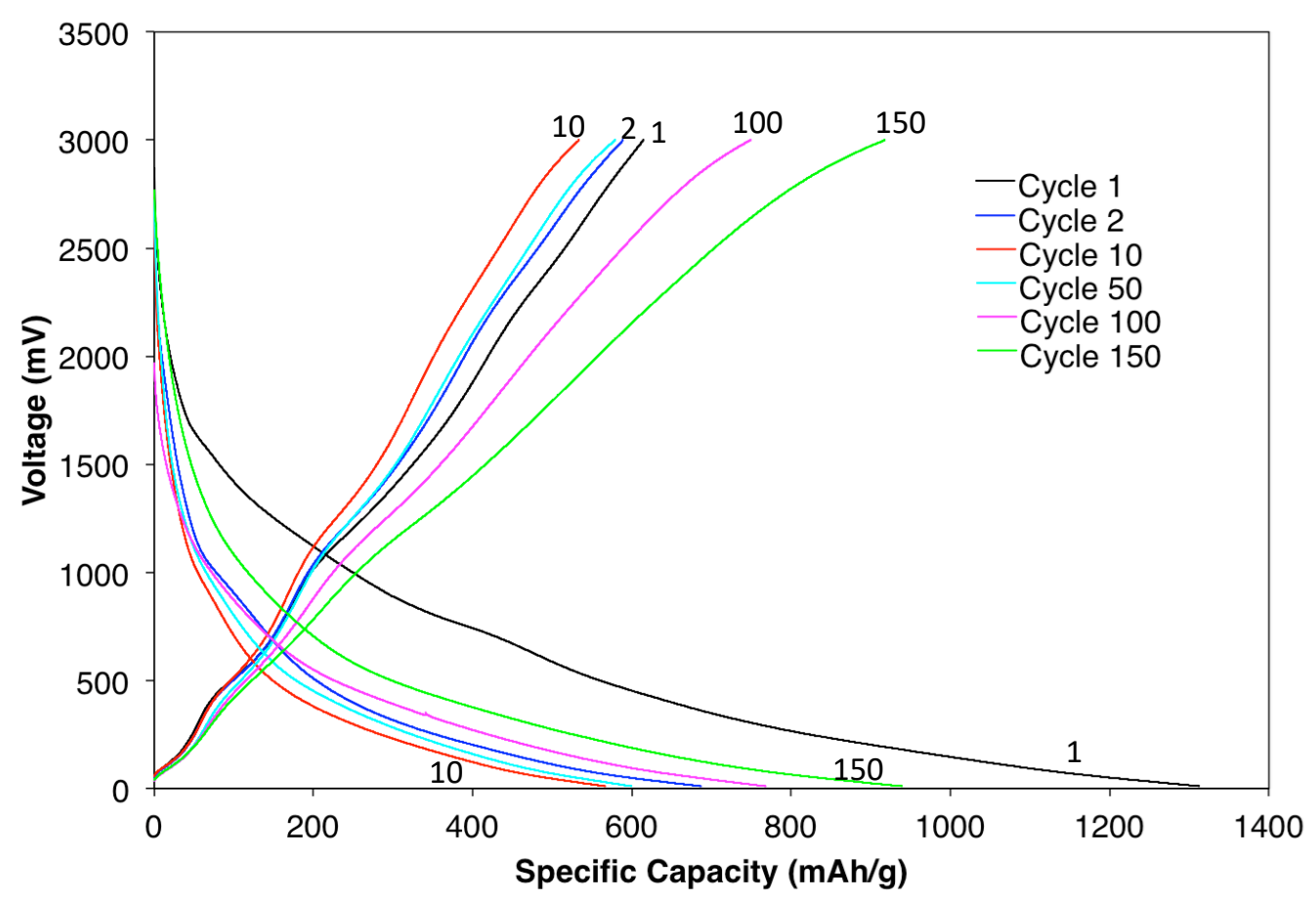

Figure 12: Galvanostatic charge-discharge curves for $20 \% \mathrm{SnO}_{2}$-in-CNT sample

A comparison of the cycle performances during discharge of the samples is presented in Figure 13 For the first 20 cycles, all of the samples showed a decreasing trend in specific capacities. By cycle 40, however, the confined samples $(20,25$, and $30 \% \mathrm{SnO} 2-$ in-CNT) showed some recovery of capacity, a trend that continued through the hundredth cycle. The unconfined sample initially had good performance but continued decreasing in capacity with cycling and did not see the recovery achieved with the confined samples. This recovery of capacity can be attributed to an electrochemical milling process that is sometimes observed with cycling of LIB electrode materials ${ }^{25}$ and also to the improved reversibility of the first reaction step of $\mathrm{SnO}_{2}$ reacting with $\mathrm{Li}^{+}$ions to form metallic $\mathrm{Sn}$ 
and $\mathrm{Li}_{2} \mathrm{O}$. In studies with nanoscale $\mathrm{SnO}_{2}$ anodes, it was found that there was a greater reversibility of this first reaction step, giving a theoretical capacity of $1490 \mathrm{mAh} / \mathrm{g} .{ }^{10} \mathrm{With}$ the electrochemical milling of $\mathrm{SnO}_{2}$ and metallic $\mathrm{Sn}$ in the anode material, there could be a reduction of the particulate size and exposure of unreacted surfaces allowing for an improvement in the observed specific capacity. The CNT alone, as expected, had a low but stable value for specific capacity. Of the groups, the best capacity is observed with the $20 \%$ $\mathrm{SnO}_{2}$-in-CNT sample. The values of specific capacity for the samples are tabulated in Table 3.

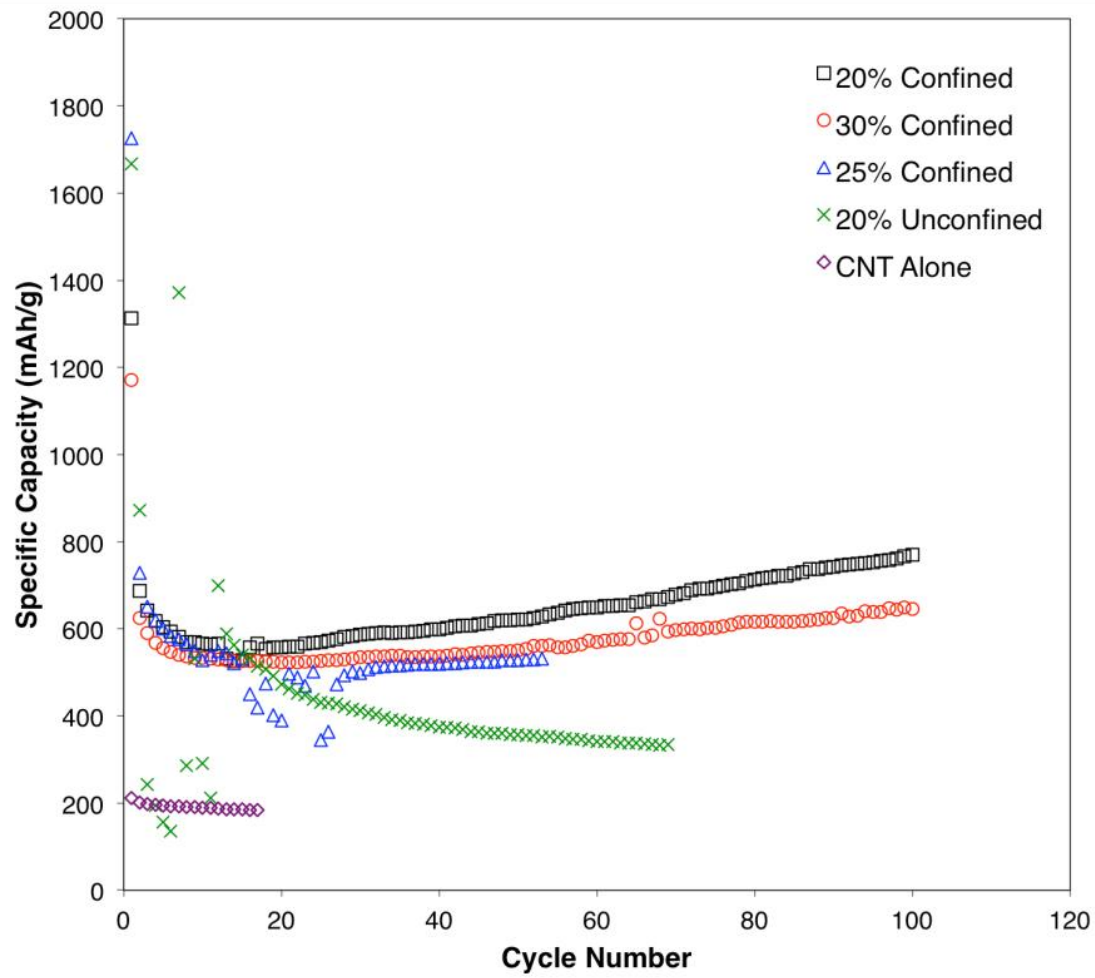

Figure 13: Cycle performances for the various control and experimental group samples 
Table 3: Tabulated values of specific capacity for various cycles.

\begin{tabular}{|l|l|l|l|l|l|l|}
\hline & \multicolumn{5}{|c|}{ Specific Capacity $(\mathrm{mAh} / \mathrm{g})$} \\
\hline & Cycle 1 & Cycle 2 & Cycle 10 & Cycle 20 & Cycle 40 & Cycle 100 \\
\hline $20 \% \mathrm{SnO}_{2}$-in-CNT & 1312.3 & 686.5 & 566.3 & 558.3 & 599.4 & 770.6 \\
\hline $25 \% \mathrm{SnO}_{2}$-in-CNT & 1725.5 & 728.3 & 527.5 & 390.4 & 519.7 & - \\
\hline $30 \% \mathrm{SnO}_{2}$-in-CNT & 1170.4 & 625.3 & 533.3 & 523.5 & 537.2 & 645.9 \\
\hline $20 \% \mathrm{SnO}_{2}$-out-CNT & 1666.7 & 871.7 & 531.4 & 491.4 & 378.3 & - \\
\hline $\mathrm{CNT}$ Alone & 211.2 & 201.6 & 190.4 & 183.5 & - \\
\hline
\end{tabular}

Figure 14 shows the cyclic performance during discharge of the $20 \% \mathrm{SnO}_{2}$-in-CNT for 200 cycles with a testing rate of $100 \mathrm{mAhg}^{-1}$ which very clearly shows the trend in initial specific capacity decrease for the first 15 cycles and subsequent increase for the remaining life of the cell through 200 cycles. The rate at which the specific capacity increased was fairly constant through cycle 100 and then increased slightly through cycle 200. The values of interest for the specific capacities at various cycle numbers were 1312.3, $686.5,770.6,943.1$, and $1069.7 \mathrm{mAh} / \mathrm{g}$ at cycles $1,2,100,150$, and 200, respectively. 


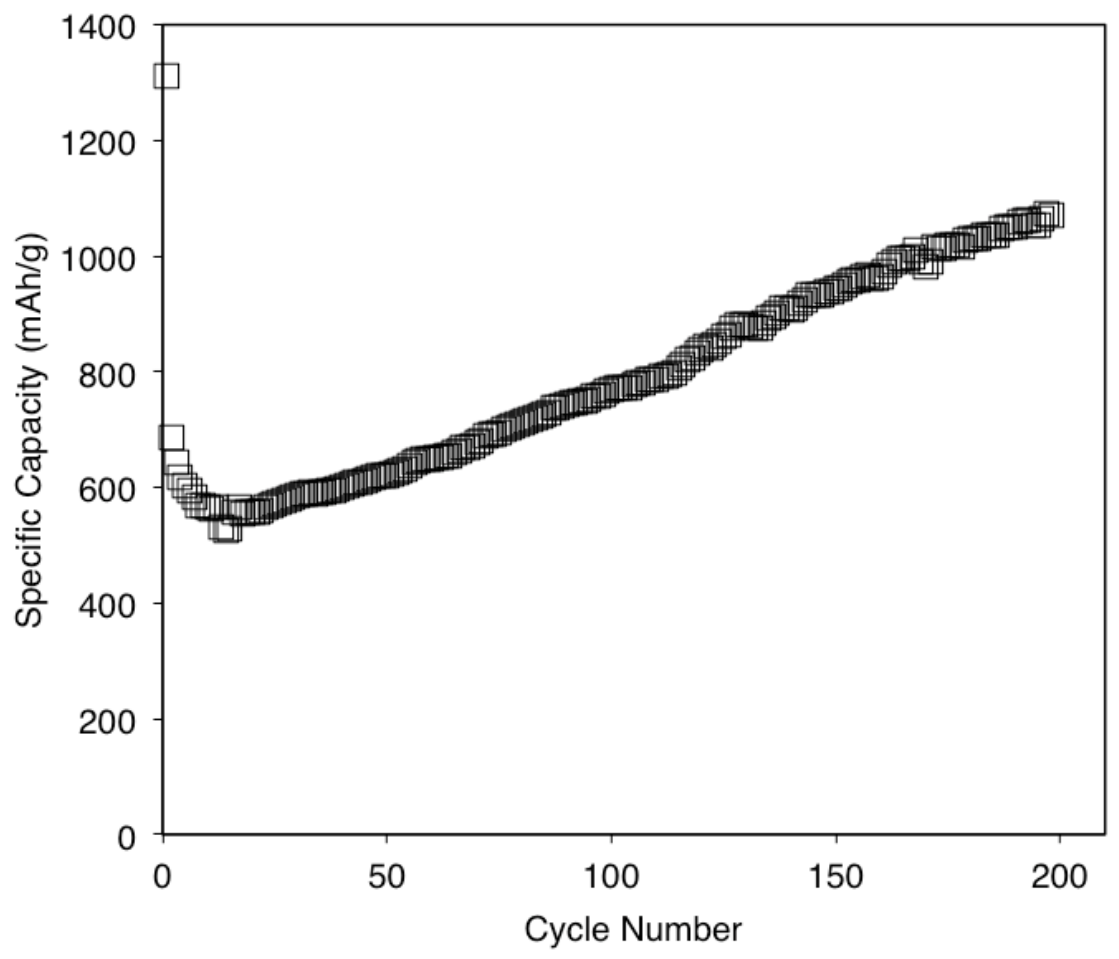

Figure 14: Cycle performance of $20 \% \mathrm{SnO}_{2}$-in-CNT for 200 cycles at $100 \mathrm{mAhg}^{-1}$ 


\section{CHAPTER V \\ CONCLUSIONS}

This thesis investigated the electrochemical performance and structural characteristics of composite lithium ion battery (LIB) anode materials containing $\mathrm{SnO}_{2}$ nanoparticles confined within the inner channels of multiwalled carbon nanotubes. The technique used to deposit the active anode material onto a current collector (nickel foam substrate) was electrostatic spray deposition (ESD). The parameters for ESD were optimized to obtain films with the desired microstructure. Various $\mathrm{SnO}_{2}$-to-CNT ratios were tested electrochemically $(10 \%, 20 \%, 25 \%$, and $30 \%)$ and the $20 \% \mathrm{SnO}_{2}$ confined within the CNT inner channels (denoted $20 \% \mathrm{SnO}_{2}$-in-CNT in this text) showed the most promising performance electrochemically. It was found with cycle performance testing that the specific capacity of the cells increased through 200 cycles with the $20 \%$ and $30 \% \mathrm{SnO}_{2-}$ in-CNT samples, but with higher specific capacity for the $20 \%$ confined samples.

The third chapter of this manuscript detailed the experimental methods and techniques used to analyze the materials, including the optimized parameters for ESD for these materials and for the desired active material film morphology (porous). These parameters were a temperature of $300^{\circ} \mathrm{C}$, a flow rate of $\sim 4 \mathrm{~mL} /$ hour for the dispensing of the precursor solution from the syringe, and an applied voltage of $5-8 \mathrm{kV}$, adjusted to give the best spray of atomized solution (even, conical shape).

Chapter four detailed the results of the analytical methods, SEM, TEM, and XRD, and of the electrochemical tests that were carried out. XRD confirmed that the procedure used did give the desired output of $\mathrm{SnO}_{2}$, which had been created via oxidation of a tin (IV) 
acetate precursor. Additionally, there was overlap between the main CNT peak and the $\mathrm{SnO}_{2}$ peaks and the main contribution to the XRD patterns of the $\mathrm{SnO}_{2}$-in-CNT and $\mathrm{SnO}_{2}$ out-CNT groups was the $\mathrm{SnO}_{2}$. SEM was used to show that the films deposited had the desired morphology for electrochemical testing, showing an even, porous thin film material with good coating of the nickel foam substrate. TEM showed that there was confinement of the $\mathrm{SnO}_{2}$ particles within the inner channel of the MWCNTs using the procedure detailed in chapter three. Finally, electrochemical testing was conducted for the various control and experimental groups and an interesting trend in initial capacity loss and eventual capacity recovery with cycling was observed for the $\mathrm{SnO}_{2}$-in-CNT confined samples. This same recovery of capacity was not observed with the control group samples, and the best performance was observed with the $20 \%$ confined sample.

The future work recommended is to continue trying other weight ratios of $\mathrm{SnO}_{2}$-inCNT to determine the absolute optimum value. Additionally, the cycled batteries should be disassembled and TEM and SEM analysis carried out to analyze the microstructure, morphology, and nanostructure of the anodes after cycling. This would allow a better observation and understanding of the changes taking place during increased cycling to prove the reason for the observed increase in capacity. The anodes should also be paired with a commercially relevant cathode material and tested as a full cell to observe full cell performance. Finally, the structure tested for this composite material, with metal oxide confined within a CNT should be tested with other metal oxides or metals that could be improved by this structure. 


\section{LIST OF REFERENCES}

1. J. Cabana, L. Monconduit, D. Larcher, and M. R. Palacín, Adv. Mater., 22, 170-192 (2010).

2. A. Abouimrane et al., Nanotechnology for Lithium-Ion Batteries Y. Abu-Lebdeh and I. Davidson, Editors, p. 1-362, Springer US, New York, NY, (2013)

http://link.springer.com/10.1007/978-1-4614-4605-7.

3. M. Endo, C. Kim, K. Nishimura, T. Fujino, and K. Miyashita, Carbon N. Y., 38, 183197 (2000).

4. H. Bin Wu, J. S. Chen, H. H. Hng, and X. W. D. Lou, Nanoscale, 4, 2526-42 (2012) http://www.ncbi.nlm.nih.gov/pubmed/22460594.

5. G. Wu et al., Appl. Surf. Sci., 315, 400-406 (2014)

http://dx.doi.org/10.1016/j.apsusc.2014.07.188.

6. G. Du et al., Electrochim. Acta, 55, 2582-2586 (2010)

http://linkinghub.elsevier.com/retrieve/pii/S0013468609015187.

7. L. Zou et al., Carbon N. Y., 49, 89-95 (2011)

http://linkinghub.elsevier.com/retrieve/pii/S0008622310006226.

8. R. Agrawal, A. Nieto, H. Chen, M. Mora, and A. Agarwal, ACS Appl. Mater.

Interfaces, 5, 12052-7 (2013) http://www.ncbi.nlm.nih.gov/pubmed/24236402.

9. C. Chen et al., ECS Trans., 61, 155-163 (2014).

10. J. Guo, B. Jiang, X. Zhang, and H. Liu, J. Power Sources, 262, 15-22 (2014)

http://dx.doi.org/10.1016/j.jpowsour.2014.03.085.

11. A. Dhanabalan, X. Li, R. Agrawal, C. Chen, and C. Wang, Nanomaterials, 3, 606614 (2013) http://www.mdpi.com/2079-4991/3/4/606/.

12. C. Chen, R. Agrawal, and C. Wang, in Proc. of SPIE, N. K. Dhar and A. K. Dutta, Editors, vol. 9865, p. 986507 (2016)

http://proceedings.spiedigitallibrary.org/proceeding.aspx?doi=10.1117/12.2228905.

13. C. Chen, R. Agrawal, Y. Hao, and C. Wang, ESC Solid State Sci. Technol., 2, 30743077 (2013).

14. C. K. Chan et al., Nat. Nanotechnol., 3, 31-35 (2008)

http://www.nature.com/doifinder/10.1038/nnano.2007.411.

15. W. Chen, Z. Fan, L. Gu, X. Bao, and C. Wang, Chem. Commun. (Camb)., 46, 39053907 (2010). 
16. Y. Yu et al., Angew. Chemie Int. Ed., 48, 6485-6489 (2009)

http://doi.wiley.com/10.1002/anie.200901723.

17. X. Li, A. Dhanabalan, L. Gu, and C. Wang, Adv. Energy Mater., 2, 238-244 (2012) http://doi.wiley.com/10.1002/aenm.201100380.

18. J. Chmiola et al., Science (80-. )., 313, 1760-1763 (2006).

19. C. Chen, R. Agrawal, and C. Wang, 9865, 986507 (2016)

http://proceedings.spiedigitallibrary.org/proceeding.aspx?doi=10.1117/12.2228905.

20. R. Agrawal, C. Chen, and C. Wang, in Proc. of SPIE, N. K. Dhar and A. K. Dutta, Editors, vol. 9865, p. 986508 (2016)

http://proceedings.spiedigitallibrary.org/proceeding.aspx?doi=10.1117/12.2228899.

21. Y. Yu, Y. Shi, C. H. Chen, and C. L. Wang, J. Phys. Chem. C, 112, 4176-4179 (2008).

22. J. Zeleny, Phys. Rev., 3, 69-91 (1914).

23. A. Cao, C. Xu, J. Liang, D. Wu, and B. Wei, Chem. Phys. Lett., 344, 13-17 (2001).

24. Y. Yu, Y. Shi, and C.-H. Chen, Nanotechnology, 18, 55706 (2007)

http://stacks.iop.org/0957-

4484/18/i=5/a=055706?key=crossref.47ff47cbbe3ad4a45533f4eb361e9cf4.

25. D. W. Zhang, C. H. Chen, J. Zhang, and F. Ren, Chem. Mater., 17, 5242-5245 (2005). 